\title{
Mechanisms of oat (Avena sativa L.) acclimation to phosphate deficiency
}

\author{
Ewa Zebrowska $^{1,2}$, Marta Milewska ${ }^{1}$, Iwona Ciereszko ${ }^{\text {Corresp. } 1}$ \\ 1 Department of Plant Physiology, University of Bialystok, Bialystok, Poland \\ 2 Department of Physiology, Medical University of Bialystok, Bialystok, Poland \\ Corresponding Author: Iwona Ciereszko \\ Email address: icier@uwb.edu.pl
}

Background. Deficiency of available forms of phosphorus is common in most soils and causes reduction of crop plants growth and yield. Recently, model plants responses to phosphate (Pi) deficiency have been intensively studied. However, acclimation mechanisms of cereals like oat (Avena sativa L.), to low Pi stress remains not fully understood. Oat plants have been usually cultured on poor soils, with a low nutrients content, but their responses to such conditions are not well known, therefore the main goal of the study was to investigate the mechanisms that enable oat plants to grow under low Pi conditions. Methods. Four oat cultivars (A. sativa, cv. Arab, Krezus, Rajtar and Szakal) were grown for three weeks in a nutrient media with various $P$ sources: inorganic $\mathrm{KH}_{2} \mathrm{PO}_{4}$ (control), organic - phytate (PA) and with no phosphate (-P). The effects of $\mathrm{Pi}$ deficiency on the level of $P$, oat growth parameters, intensity of photosynthesis, plant productivity, root exudation ability, localization, activity and isoforms of acid phosphatases, enzymes involved in Pi mobilization, were estimated. In addition the effect of mycorrhization on plants growth was also observed. Results. All studied oat cultivars grown on Pi-deficient media had significantly decreased Pi content in the tissues. Pi deficiency caused inhibition of shoot growth, but generally it did not affect root elongation; root diameter was decreased, root/shoot ratios increased, whereas PA plants showed a similar growth to control. Photosynthesis rate and productivity parameters decreased under low Pi nutrition, however, sugar content generally increased. Studied oat cultivars did not respond to low Pi via increased exudation of carboxylates from the roots, as $\mathrm{pH}$ changes in the growth media were not observed. Pi starvation significantly increased the activity of extracellular and intracellular acid phosphatases (APases) in comparison to the control plants. Three major APase isoforms were detected in oat tissues and the isoform pattern was similar in all studied conditions, usually with a higher level of one of the isoforms under Pi starvation. Generally no significant effects of mycorrhizal colonization on growth of oat cultivars was observed. Discussion. We postulated that acid phosphatases 
played most important role in oat cultivars acclimation to Pi deficiency, especially extracellular enzymes involved in Pi acquisition from soil organic P esters. These APases are mainly located in the epidermis of young roots, and may be released to the rhizosphere. On the other hand, intracellular APases could be involved in fast Pi remobilization from internal sources. Our study showed that oat, in contrast to other plants, can use phytates as the sole source of P. The studied oat cultivars demonstrated similar acclimation mechanisms to Pi deficiency, however, depending on stress level, they can use different pools of acid phosphatases. 


\section{Mechanisms of oat (Avena sativa L.) acclimation to phosphate deficiency}

2

3 Ewa Żebrowska ${ }^{1,2}$, Marta Milewska ${ }^{1}$, Iwona Ciereszko 1 *

4

5 'Department of Plant Physiology, Institute of Biology, University of Bialystok, Bialystok, 6 Poland

$7 \quad{ }^{2}$ Department of Physiology, Medical University of Bialystok, Bialystok, Poland

9

10

11

12

13

14

16

17
*Corresponding author

Iwona Ciereszko

Institute of Biology, University of Bialystok,

Ciolkowskiego1J, 15-245 Bialystok, Poland

E-mail: icier@uwb.edu.pl

\ These authors contributed equally to this work

Short title: Oat acclimation to Pi deficiency 


\section{Abstract}

Background. Deficiency of available forms of phosphorus is common in most soils and causes reduction of crop plants' growth and yield. Recently, model plants' responses to phosphate (Pi) deficiency have been intensively studied. However, acclimation mechanisms of cereals like oat (Avena sativa L.) to low Pi stress remains not fully understood. Oat plants have been usually cultured on poor soils, with a low nutrient content, but their responses to such conditions are not well known. Therefore, the main goal of the study was to investigate the mechanisms that enable oat plants to grow under low Pi conditions.

Methods. Four oat cultivars (A. sativa, cv. Arab, Krezus, Rajtar and Szakal) were grown for three weeks in nutrient media with various $\mathrm{P}$ sources: inorganic $-\mathrm{KH}_{2} \mathrm{PO}_{4}$ (control), organic phytate (PA) and with no phosphate (-P). The effects of Pi deficiency on the level of P, growth parameters, intensity of photosynthesis, plant productivity, root exudation ability, localization, activity and isoforms of acid phosphatases, enzymes involved in Pi mobilization were estimated. In addition the effect of mycorrhization on plants growth was also monitored.

Results. All studied oat cultivars grown on Pi-deficient media had significantly decreased Pi content in the tissues. Pi deficiency caused inhibition of shoot growth, but generally, it did not affect root elongation; root diameter was decreased, root/shoot ratios increased, whereas PA plants showed a similar growth to control. Photosynthesis rate and productivity parameters decreased under low Pi nutrition, however, sugar content generally increased. Studied oat cultivars did not respond to low Pi via increased exudation of carboxylates from the roots, as $\mathrm{pH}$ changes in the growth media were not observed. Pi starvation significantly increased the activity of extracellular and intracellular acid phosphatases (APases) in comparison to the control plants. Three major APase isoforms were detected in oat tissues and the isoform pattern was similar in 53 all studied conditions, usually with a higher level of one of the isoforms under Pi starvation.

54 Generally, no significant effects of mycorrhizal colonization on growth of oat cultivars were 55 observed. 
56 Discussion. We postulated that acid phosphatases play an important role in oat cultivars for 57 acclimation to Pi deficiency, especially extracellular enzymes involved in Pi acquisition from

soil organic P esters. These APases are mainly located in the epidermis of young roots, and may be released to the rhizosphere. On the other hand, intracellular APases could be involved in fast Pi remobilization from internal sources. Our study showed that oat, in contrast to other plants, can use phytates as the sole source of $\mathrm{P}$. The studied oat cultivars possess similar acclimation mechanisms to Pi deficiency, however, depending on the stress level, they can use different pools of acid phosphatases.

\section{Introduction}

Plants require a wide range of mineral nutrients for normal growth and development. Phosphorus (P) is one of the least accessible macronutrients. It plays key roles in many plant processes, such as organic compound synthesis - photosynthesis and respiration or regulation of enzyme activities and gene expression (Vance et al. 2003; Rychter and Rao 2005; Hammond et al. 2008; Amtmann et al.2009). Plants absorb only inorganic phosphate, $\mathrm{Pi}\left(\mathrm{HPO}_{4}{ }^{2-}\right.$ and $\left.\mathrm{H}_{2} \mathrm{PO}_{4}{ }^{-}\right)$ therefore, although the total amount of $\mathrm{P}$ in the soil may be high, its availability for plants is low (Schachtman et al. 1998; Vance et al. 2003; Raghothama and Karthikeyan 2005). In acid soils, phosphorus forms poorly soluble complexes with iron $(\mathrm{Fe})$, and aluminium $(\mathrm{Al})$, while in neutral to alkaline soils it combines with calcium (Ca) (Holford 1997; Smith et al. 2003). It is assumed that organic P (mainly phytate and its derivatives), representing even up to $80 \%$ of total $\mathrm{P}$ in soil, is also unavailable for plants (Schachtman et al. 1998, Gerke 2015). Phosphate deficiency is thus one of the main limiting factors for plant productivity and crop yield. Modern agriculture strongly depends on P-fertilizer application, however, plants can absorb only up to $25 \%$ of $\mathrm{Pi}$ from mineral fertilizers (Hermans et al. 2006; Lynch 2011; Shenoy and Kalagudi 2005). Furthermore, the resources of $\mathrm{P}$ for fertilizer production (mined rock phosphates) are nonrenewable and the longevity of phosphate reserves is limited (up to several hundred years at current production rates) (Gerke 2015; Cordell et al. 2009). Moreover, fertilizer prices are rising mainly due to the expensive extraction of low quality phosphate rock and dependency of most countries on fertilizer import (the vast majority of global reserves is held only by a few countries). Currently, most scientists agree that there is a strong need for increased recycling and 
86 efficient use of phosphorus to sustain or extend food production in the context of a growing 87 human population (Cordell et al. 2009; Lynch 2011; Scholz et al. 2014; Faucon et al. 2015).

Plants have evolved various morphological, physiological and biochemical adaptive responses to overcome phosphate deficiency that include increased Pi uptake from the soil and/or more efficient Pi use in the tissues (Smith et al. 2003; Raghothama and Karthikeyan 2005; Hammond et al. 2008; Richardson et al. 2009; Tran et al. 2010; Faucon et al. 2015). Efficient use of acquired $\mathrm{Pi}$ in plant tissues under Pi starvation is possible through a variety of physiological and metabolic adaptations, such as alternative metabolic photosynthetic pathways, glycolysis and mitochondrial electron transport or enhanced photorespiration and carbon metabolism (Maleszewski et al. 2004; Ciereszko and Kleczkowski 2005; Rychter and Rao 2005; Amtmann et al. 2009; Plaxton and Tran 2011). Plants grown under Pi deficiency can also allocate a greater proportion of assimilates to root growth at the expense of shoot growth (Ciereszko et al. 1999; Hermans 2006; Hammond and White 2008). It was demonstrated that even small changes in root morphology could be important for better exploration of soil and influences Pi uptake (Wissuwa 2003; Lynch 2011; Péret et al. 2014; Stetter et al. 2017). Changes in root morphology/architecture under Pi deficiency mainly include: an increase or decrease of root length, promotion of lateral root growth, enhancement of root hair development and proteoid root (clusters of lateral roots) formation (Neumann et al. 2000; Williamson et al. 2001; Niu et al. 2013). Proteoid roots not only increase root surface area, but also secrete many compounds, such as organic acids and acid phosphatases that increase Pi availability (Lambers et al. 2012, 2015). In response to Pi starvation, plants produce a shallow branched root system easily exploring large areas of the upper layer of soil in search of Pi-rich patches. Recently, several studies have addressed the function played by transcription factors, such as MYB62, WRKY75, PHR1 and ZAT6 or miRNAs and phytohormones in root architecture modification in response to low Pi nutrition (Tran et al. 2010; Niu et al. 2013; Péret et al. 2014; Zhang et al. 2014; Baker et al. 2015; Stetter et al. 2017). Recent studies have also shown that root architecture changes are controlled by local signals of Pi availability in the soil rather than internal Pi content in tissues (Thibaud et al. 2010; Hoehenwarter et al. 2016). Root surface area and the ability to uptake Pi from the soil may be also increased by mycorrhizal hyphae. It is 
117 estimated that more than $80 \%$ of the land plants form arbuscular mycorrhizal symbioses (AM)

118 with soil fungi (mainly Glomeromycota) (Smith et al. 2003; Karandashov and Bucher 2005;

119 Smith and Smith 2011). AM fungi stimulate host plant growth, especially by enhancing Pi

120 uptake in order to receive organic compounds. Pi uptake of colonized roots may even be several

121 times higher than in non-infected roots (Raghothama and Karthikeyan 2005; Shu et al. 2014;

122 Baker et al. 2015). Two pathways of Pi acquisition are known: via root epidermal cells and root

123 hairs, and via AM fungi that deliver Pi directly to the root cortex and may represent $70 \%$ of the

124 total acquired phosphate (Smith and Smith 2011; Yang et al. 2012). Efficient Pi uptake requires

125 active Pi transporters, both of fungal and plant origin. It was reported that numerous plant Pi

126 transporter genes could be induced by mycorrhizal fungi, however, their expression varied

127 depending on AM fungi species (Ceasar et al. 2014; Baker et al. 2015).

128 Plant roots can secrete organic acids, protons and phenolics that increase the availability

129 of inorganic, poorly soluble forms of $\mathrm{P}$, such as $\mathrm{Ca}, \mathrm{Fe}$, and $\mathrm{Al}$ phosphates. Malic and citric

130 acids are predominant organic acids found in root exudates of Pi-deficient plants (Vance et al.

131 2003; Richardson et al. 2009; Wang et al. 2015, 2017). The enhanced organic acid secretion is

132 determined mainly by increased activities of phosphoenolpyruvate carboxylase, malate

133 dehydrogenase and citrate synthase (Plaxton and Tran 2011; Baker et al. 2015). Another

134 mechanism of plant response to Pi deficiency in the environment is increased production and

135 secretion of enzymes that facilitate the hydrolysis of organic forms of phosphorus, particularly

136 extracellular acid phosphatases (APases) (Duff et al. 1994; Tran et al. 2010). Acid phosphatases

137 (orthophosphoric monoester phosphohydrolases, EC 3.1.3.2) hydrolyse different forms of

138 organic $\mathrm{P}$, usually in a non-specific manner. APase activity has been shown in cells of various

139 organisms, like bacteria, yeast, and plants (Duff et al. 1994; Żebrowska and Ciereszko 2009;

140 Tran et al. 2010). APases are involved in the uptake, allocation and recycling of Pi, processes

141 which are crucial for cellular metabolism and bioenergetics. Expression of APase genes is

142 affected by different environmental factors, including Pi deficit; enhanced APase synthesis and

143 activity was also observed under salinity and water-deficit stress (Tran et al. 2010). Secretion of

144 APases into the rhizosphere is a typical response to Pi-starvation and has been documented in

145 various models and crop plants, including Arabidopsis, barley, lupine, oat, rape, rice, soybean,

146 tomato and wheat (George et al. 2008; Zhang et al. 2010; Ciereszko et al. 2011 a, b; Żebrowska

147 et al. 2011; del Vecchio et al 2014; Tian and Liao 2015; Lu et al. 2016). The high secretion of 
148 acid phosphatases was observed in white lupine roots, especially in proteoid regions (Wasaki et 149 al. 2009; Tang et al. 2013). What is more, extracellular APase activity was shown to increase 150 during proteoid root development, whereas internal APase activity was relatively constant (Tang 151 et al. 2013). Purple acid phosphatases are the most investigated enzymes among APases (Olczak 152 et al. 2003; Tran et al. 2010), e.g. three of them (AtPAP10, AtPAP12 and AtPAP26) can be 153 secreted under Pi deficiency from A. thaliana roots (Del Vecchio et al. 2014; Tian and Liao

154

155

156

157

158

159

160

161

162

163

164

165

166

167

168

169

170

171

172

173

174

175

176

177

178

2015). Purple APases may also participate in cell wall biosynthesis, carbon metabolism or biotic stress tolerance (Tran et al. 2010; Tian and Liao 2015). Under low Pi conditions, the activity of internal APases (pivotal for Pi mobilizing from P-rich cell organelles) is also increased (Tran et al. 2010; Zhang et al. 2010; Ciereszko et al. 2011; Tian and Liao 2015). Pi deficiency can also enhance the release of specific enzymes, such as phytases (myo-inositol hexakisphosphate phosphohydrolase, EC 3.1.3.8, 3.1.3.26), that catalyse the hydrolysis of phytates, or nucleases and apyrases that hydrolyse nucleic acids and extracellular ATP in the soil (Vance et al. 2003; Richardson et al. 2009; Gerke 2015).

Hundreds of genes associated with plant responses to Pi deficiency have been identified in the model plant $A$. thaliana and certain crop plants, mainly rice (Misson et al. 2005; Thibaud et al. 2012; Li et al. 2012; Péret et al. 2014; Zhang et al. 2014). Recently, Pi signalling networks and signalling molecules have been intensively studied (Thibaud et al. 2012; Zhang et al. 2014; Baker et al. 2015; Hoehenwarter et al. 2016). Quantitative trait loci analyses show that Pi acquisition traits are complex and regulated by multiple genetic loci and so far have not been often used by breeders (Wissuwa 2003; Lynch 2011; Niu et al. 2013). Recently, with development of transgenic methods, the number of genes improving $\mathrm{P}$ efficiency that have been successfully introduced into crop species has been constantly rising in laboratory conditions (Tran et al. 2013; Niu et al. 2013; Zhang et al. 2014). However, even interesting transgenic lines of cereals are not commercially available, not only because of technical problems but also due to the public opposition to genetically modified food.

Mechanisms of plant acclimation to phosphate deficiency are well documented for model plants, however, there are not many studies on acclimation of cereal plants, such as oat, to Pi deficiency. Oat (Avena sativa L.) is an important crop plant in agriculture, human and animal nutrition as well as cosmetic and pharmaceutical industry (Butt et al. 2008). Oat plants have been always grown on worse, less productive agricultural lands and poor soils, with a low Pi 
179

180

181

182

183

184

185

186

187

188

189

190

191

192

193

194

195

196

197

198

199

200

201

202

203

204

205

206

207

208

concentration, but their acclimation mechanisms to such conditions are still not fully understood.

Therefore, the main goal of our study was to provide a comprehensive analysis of these

mechanisms and to assess the differences between oat cultivars. We investigated a wide array of physiological responses of four oat cultivars to early and intermediate stress of Pi deficiency during a period critical to tiller formation and further plant productivity. In particular, we focused on the activity (and localization) of acid phosphatases to evaluate their role in oat response to $\mathrm{Pi}$ deficiency. The present study also investigated the effects of phytate as the sole organic P source in the nutrient medium on the growth of oat plants. With rising P-fertilizer prices, selecting crop cultivars with improved nutrient acquisition and P-use efficiency is an important component of an integrated strategy for solving the problem of phosphate deficiency.

\section{Materials \& Methods}

\section{Plant material}

Four oat (Avena sativa L.) commercial cultivars (recommended for farmers): Arab (registered in 2004), Krezus (2005) Rajtar (2004) and Szakal (2000) were selected, among several other oat genotypes, in the preliminary experiments including APase secretion, and used for the further studies. Oat seedlings, after 6-7 days of germination (Petri dishes, in a growth chamber), were grown for 1-3 weeks in nutrient media with contrasting phosphorus source: inorganic $-\mathrm{KH}_{2} \mathrm{PO}_{4}($ control, $+\mathrm{P})$, organic - phytic acid (PA) and with no phosphate (-P) as described previously (Ciereszko et al. 2011). +P medium contained: $\mathrm{Ca}\left(\mathrm{NO}_{3}\right)_{2}(4.4 \mathrm{mM})$, $\mathrm{MgSO}_{4}(2.7 \mathrm{mM}), \mathrm{KNO}_{3}(1.5 \mathrm{mM}), \mathrm{KH}_{2} \mathrm{PO}_{4}(1 \mathrm{mM})$, Fe-EDTA $(76 \mu \mathrm{M}), \mathrm{H}_{3} \mathrm{BO}_{3}(43 \mu \mathrm{M})$, $\mathrm{MnCl}_{2}(9 \mu \mathrm{M}), \mathrm{CuSO}_{4}(0.3 \mu \mathrm{M}), \mathrm{ZnSO}_{4}(0.8 \mu \mathrm{M}), \mathrm{H}_{2} \mathrm{MoO}_{4}(0.1 \mu \mathrm{M})$; PA medium contained phytic acid $(0.1 \mathrm{mM})$ (instead $\mathrm{KH}_{2} \mathrm{PO}_{4}$; concentration chosen after preliminary studies) and -P medium - $\mathrm{KCl}(2 \mathrm{mM})$ (instead $\left.\mathrm{KH}_{2} \mathrm{PO}_{4}\right)$. Oat cultivars were cultured in a separate plastic containers (about 15 seedlings per 51 of nutrient medium); growth media were adjusted to $\mathrm{pH}$ 5.2 (adding drops of $1 \mathrm{~N} \mathrm{NaOH}$ ), continuously aerated and replaced every 4-5 days. Oat plants were cultured under controlled conditions - in a growth chamber with a light period of $16 \mathrm{~h}(8 \mathrm{~h}$ dark), PAR - $150 \mu \mathrm{mol} \mathrm{m} \mathrm{m}^{-2} \mathrm{~s}^{-1}$, temperature $-23 / 19^{\circ} \mathrm{C}$ (day/night) and relative humidity around $60 \%$. The plant material was collected 3 - 4 hours after the beginning of the light period. Growth analyses were performed directly, and the following growth parameters were calculated: leaf 
209

210

211

212

213

214

215

216

217

218

219

220

221

222

223

224

225

226

227

228

229

230

231

232

233

234

235

236

237

area ratio (LAR), relative growth rate (RGR), stem weight ratio (SWR) and unit leaf rate (ULR), according to the method of Miranda et al. (2011). Root exudation was determined by measuring the $\mathrm{pH}$ of nutrient media and rhizosphere acidification on agar sheets with bromocresol purple, as described by Neumann et al. (2000) (Suppl. material Fig. S3). Oat plants were harvested for analyses after 1, 2 and 3 weeks of growth in various nutrient media.

\section{Phosphorus content measurements}

Inorganic phosphate (Pi) content in the leaves and roots of oat cultivars under the studied conditions was determined using a phosphomolybdate colorimetric assay, as described before (Ciereszko et al. 2011). Aliquots of $0.5 \mathrm{~g}$ of roots/leaves were frozen in liquid nitrogen and homogenized in $10 \%(\mathrm{v} / \mathrm{v}) \mathrm{TCA}$ at $4^{\circ} \mathrm{C}$, diluted with $5 \%$ TCA, incubated for $30 \mathrm{~min}$ and then centrifuged $(10 \mathrm{~min}$ at $10,000 \times g)$. The Ames reagent was added to the tissue extract, the samples were incubated for $20 \mathrm{~min}$ at $25^{\circ} \mathrm{C}$ and absorbance was read at $710 \mathrm{~nm}$ (Beckman DU 730). Total phosphorus (Pt, Supporting Information, Fig. S1) was determined in tissue samples ( $0.05 \mathrm{~g}$ dry weight) after mineralization with concentrated $\mathrm{H}_{2} \mathrm{SO}_{4}$ and $\mathrm{HNO}_{3}$; Pi content was determined as described above.

\section{Photosynthesis rate estimations}

Measurements were taken using a LI-COR $\mathrm{CO}_{2} / \mathrm{H}_{2} \mathrm{O}$ analyser (LI-6262, LI-COR Inc., Lincoln, Nebraska, USA) under conditions similar to seedling cultures: photosynthetic photon flux density $200 \mu \mathrm{mol}$ (photon) $\mathrm{m}^{-2} \mathrm{~s}^{-1}, \mathrm{O}_{2}$ and $\mathrm{CO}_{2}$ at atmospheric concentrations, temperature of $25^{\circ} \mathrm{C}$, as described previously (Maleszewski et al. 2004). Chlorophylls and carotenoids were extracted from the leaves with $100 \%$ methanol at $70^{\circ} \mathrm{C}$ and determined spectrophotometrically, according to the method of Wellburn (1994).

\section{Carbohydrate content determination}

For soluble sugar extraction, shoot and root samples $(0.5 \mathrm{~g})$ were frozen in liquid nitrogen, then ground in $80 \%$ ethanol and incubated for $20 \mathrm{~min}$ at $70^{\circ} \mathrm{C}$, subsequently centrifuged (10 min, 10,000 $\times g$ ) and washed 3 times with $80 \%$ ethanol. The precipitate was used for starch measurements, whereas the supernatant was evaporated and the residue was washed/diluted with distilled water and chloroform (1:1) and used for determination of soluble sugars as described before (Ciereszko et al. 2002). 
For starch determination, the precipitates were dried at $60^{\circ} \mathrm{C}$ for two hours, then $2 \mathrm{ml} 0.2$

239

240

241

242

243

244

245

246

247

248

249

250

251

252

253

254

255

256

257

258

259

260

261

262

263

264

265

266

$\mathrm{M} \mathrm{KOH}$ was added and boiled in a water bath for $1.5 \mathrm{~h}$. After cooling, $0.2 \mathrm{ml} 4 \mathrm{M} \mathrm{CH}_{3} \mathrm{COOH}$ and $1 \mathrm{U}$ of amyloglucosidase in $0.1 \mathrm{M}$ acetate buffer ( $\mathrm{pH} 4.6)$ was added. Samples were incubated at $37^{\circ} \mathrm{C}$ for 48 hours then heated $10 \mathrm{~min}$ in a boiling water bath. The amount of glucose (hydrolysed by amyloglucosidase from starch) was determined as described before (Ciereszko and Barbachowska 2000).

\section{Extracellular acid phosphatase activity}

Intact root systems of oat cultivars were washed (distilled water), dried and incubated at about $25^{\circ} \mathrm{C}$ with a substrate mixture $(6 \mathrm{mM} p$-nitrophenyl phosphate $(p \mathrm{NPP})$ and $1 \mathrm{mM}$ dithiothreitol in $50 \mathrm{mM} \mathrm{Na}$-acetate buffer, $\mathrm{pH}$ 5.0), (30 or $50 \mathrm{ml}$ of medium, depending on root size), according to the method described by Żebrowska et al. (2012). After incubation, $0.2 \mathrm{ml}$ of $4 \mathrm{M} \mathrm{NaOH}$ was added (to stop the reaction) to $0.2 \mathrm{ml}$ of the reaction medium; the absorbance was read at $410 \mathrm{~nm}$ (Cecil CE 2501). The measurements were performed after $15 \mathrm{~min}$ of incubation $\left[\mu \mathrm{mol} p \mathrm{NP} \min ^{-1} \mathrm{~g}^{-1} \mathrm{FW}\right.$ ]. Kinetic assay, the Lineweaver-Burk plot and the $\mathrm{K}_{\mathrm{m}}$ and $\mathrm{V}_{\max }$ were estimated for extracellular APase activity in the conditions referred above; the concentration of $p$ NPP ranged from 0 to $10 \mathrm{mM}$ (Suppl. Material, Fig. S4).

\section{Intracellular APase activity assays}

For enzyme extraction, $0.5 \mathrm{~g}$ of shoots and roots were ground in liquid nitrogen, the extraction buffer (50 mM Na-acetate, $\mathrm{pH} 5.0$ with $1 \mathrm{mM}$ DTT) was added, then extracts were centrifuged at $12,000 \times g$ for $10 \mathrm{~min}$ at $4^{\circ} \mathrm{C}$ (Ciereszko et al. 2002; Żebrowska et al. 2012). The reaction was terminated with $4 \mathrm{M} \mathrm{NaOH}$ after 5-60 min of incubation with $6 \mathrm{mM} p \mathrm{NPP}$ (in 100 $\mathrm{mM} \mathrm{Na}$-acetate buffer, $\mathrm{pH} 5.0$ ) at $37^{\circ} \mathrm{C}$ and the amount of $p$-nitrophenol was measured as described above. The measurements were taken after 15 min of incubation [ $\mu \mathrm{mol} p \mathrm{NP} \mathrm{min}^{-1}$ $\left.\mathrm{g}^{-1} \mathrm{FW}\right]$.

\section{Tissue localization of acid phosphatases}

For tissue localization of APases, hand-made cross sections of oat roots (at the maturation zone) were rinsed in Na-acetate buffer $(0.1 \mathrm{mM}, \mathrm{pH} 5.0)$ and incubated in a substrate mixture (0.2\% Fast Blue B, 0.2\% 1-naphthyl phosphate, $100 \mathrm{mM} \mathrm{Na-acetate} \mathrm{buffer,} \mathrm{pH}$ 5.0). After incubation (20 min), tissues were washed (distilled water) and photographed under a light 
267 microscope (Olympus BX41). A dark red-brown colour indicated acid APase activity in the root

268 tissues (Żebrowska et al. 2012).

\section{Analysis of acid phosphatase isoforms}

270 Root and shoot tissues of four oat cultivars $(1 \mathrm{~g})$ were ground in a mortar chilled with

271 liquid $\mathrm{N}_{2}$, then $4 \mathrm{ml}$ of extraction buffer was added (100 mM Na-acetate, pH 5.0, $2 \mathrm{mM}$ EDTA,

$27220 \mathrm{mM} \mathrm{CaCl}_{2}, 5 \mathrm{mM}$ DTT and $60 \mathrm{mg}$ PVPP), the solution was gently mixed at $4^{\circ} \mathrm{C}$ for $60 \mathrm{~min}$

273 and subsequently centrifuged at 10,000 rpm, then pellet was discarded. Equal protein amounts

274 (10 $\mu \mathrm{g}$ for individual shoots per lane and $6 \mu \mathrm{g}$ for roots) were loaded onto a discontinuous native

275 PAGE (5\% (w/v) stacking gel, 10\% (w/v) resolving gel). The native gels were run at $4{ }^{\circ} \mathrm{C}$ using a

276 mini-gel system (Hoefer SE 260, Amersham) and washed in $0.1 \mathrm{mM} \mathrm{Na-acetate}$ buffer.

277 Approximate masses of APase isoforms were determined using Full Range Rainbow Molecular

278 Weight Markers (Amersham). The fluorescence of methylumbelliferone liberated by

279 phosphatase activity was visualized under UV light (Gel Doc 2000, ver.4.1, Bio-Rad), as

280 described before (Żebrowska et al. 2012). Protein concentration in shoot and root extracts was

281 determined according to the Bradford (1976) method, at $595 \mathrm{~nm}$ (Cecil CE 2501), with BSA as

282 the standard.

283

284

285

286

287

288

289

290

291

292

293

294

\section{Effect of mycorrhizal colonization on plant growth and Pi content}

Seedlings of two oat cultivars (Arab and Krezus), treated or not treated (control) with mycorrhizal fungus Glomus intraradices (M), were cultured on a sterile sand mixture. For mycorrhizal infection, root fragments of Pelargonium sp. and Denebola sp. infected with the fungus $G$. intraradices were mixed with sand (1:10) (Nowak 2009). Plants were watered with nutrient media with different $\mathrm{P}$ source: inorganic $-\mathrm{KH}_{2} \mathrm{PO}_{4}$ (control), organic - phytic acid (PA) and without Pi (-P) (as described in the Plant Material section). Mycorrhizal colonization was determined after 4 weeks of culture in a growth chamber (controlled growth conditions as described before) by staining the roots with trypan blue, as described by Phillips and Hayman (1970). Growth parameters of oat plants and inorganic phosphate content in leaves and roots under all conditions studied was measured using methods described above.

\section{Statistical analysis}


295

296

297

298

299

300

301

302

303

304

305

306

307

308

309

310

311

312

313

314

315

316

317

318

319

320

321

322

323

324

All experiments were performed in 3-5 independent series, at different times, and all assays were carried out at least in three replicates. Standard deviation (SD) was calculated. The data were analyzed by one-way analysis of variance (ANOVA), in addition Duncan's multiple-range test was carried out (Statistica 6, StatSoft, USA). The significance level in comparisons was $\mathrm{p}<0.05$.

\section{Results}

Oat cultivars (Avena sativa L. cv. Arab, Krezus, Rajtar and Szakal) cultured for three weeks on $-\mathrm{P}$ nutrient medium showed significantly reduced Pi content and altered growth characteristics. Pi content was severely decreased already after one week of culture on -P medium and after three weeks it was decreased down to $4 \%$ of control $(+P)$ in the shoots of all tested cultivars (Fig. 1A-C) as well as the roots of cv. Arab and Rajtar, whereas in cv. Krezus and Szakal roots it was $8 \%$ of control (Fig. 1D-F). However, the plants grown on phytic acid (PA), as the sole source of phosphorus showed similar Pi content to control plants, especially in shoots (Fig. 1A-C). The reduction in Pi content in the roots of PA plants occurred after 2-3 weeks of cv. Arab and Krezus culture and was about $46 \%$ of control (Fig. 1D-F). The decrease in Pi content in -P plant tissues was accompanied by a total phosphorus decrease [see Supporting Information Fig. S1]. However, Pt content in plants grown on phytic acid was less affected, especially in roots where the Pt level was even higher (cv. Krezus roots, 3 weeks culture). The differences in phosphorus content observed between oat cultivars under study were not derived from initial differences in seed P content [see Supporting Information Fig. S1]. Plant growth was strongly affected by phosphate deficiency in plant tissues after 2-3 weeks of culture (Fig. 2, Table 1). Shoot fresh weight of -P plants of all the studied cultivars was decreased down to $40 \%$ of control after 2 weeks (Table S1) and after 3 weeks it was reduced to $24 \%$ for $\mathrm{cv}$. Arab and $15 \%$ for other oat cultivars (Table 1). Root fresh weight after two weeks of $-\mathrm{P}$ culture was lowered only in cv. Krezus and Szakal - down to $50-60 \%$ of control [see Supporting Information Table S1]. After 3 weeks, the lowest fresh mass was observed in cv. Szakal roots ( $26 \%$ of control) (Table 1). The decrease in root mass was not accompanied by the reduction in root length. After 2-3 weeks of growth, root length was approximately 1.3 times higher than in control plants [see Supporting Information Fig. S2]. -P plants had a higher root length/shoot 
325 height ratio after 2-3 weeks of growth, and it was the highest during the last week of culture (2

326 times higher than in control). Fresh weight and the root to shoot ratios of PA plants were similar

327 to control plants during three-week-culture of oat cultivars studied (Table 1, Table S1).

328 Growth and productivity parameters of plants cultured on different nutrient media were

329 calculated and were similar after two [S1 Table] and three (Table 1) weeks of plant culture. Leaf

330 area ratio (LAR) was reduced only for Arab and Krezus cultivars and ( $86 \%$ and $65 \%$ of control,

331 respectively) after 3 weeks of growth on -P medium (Table 1). Phosphate deficiency decreased

332 the shoot weight ratio (SWR) of all the studied oat cultivars; after 3 weeks of culture, SWR in -P

333 plants was about 65\% for Arab and Krezus, 71\% for Rajtar and 78\% for Szakal cultivars in

334 comparison to control (Table 1). SWR in PA plants was similar to control during the culture (a

335 decrease to $90 \%$ of control was observed only in cv. Rajtar after 3 weeks). Unit leaf rate (ULR)

336 and relative growth rate (RGR) were decreased (down to $32 \%$ of control) only for cv. Krezus

337 after 3 weeks of growth on -P medium. Surprisingly, both of these parameters were 1.4 times

338 higher in cv. Arab cultured under phosphate deficiency. PA plants showed similar ULR and

339 RGR to control plants (Table 1).

340 Phosphate deficiency significantly decreased root diameter up to $70 \%$ of control for

341 cultivar Arab, 60\% for Krezus and Rajtar and 50\% for Szakal after 3 weeks of culture (Table 1).

342 -P plants also had lower root area (except cv. Arab) down to 80\% of control for cv. Rajtar, 74\%

343 for Krezus and 57\% for Szakal. Plants cultured on phytic acid had similar root diameter and

344 surface compared to + P plants (Table 1).

345 Phosphorus deficiency did not markedly affect net the $\mathrm{CO}_{2}$ assimilation rate $\left(\mathrm{P}_{\mathrm{N}}\right)$ during

346 1-2 weeks of -P culture, whereas a significant decrease (down to 50-60\% of control) was

347 observed for all oat cultivars after 3 weeks of culture (Fig. 3 A-C). These changes were not

348 observed in PA plants. Chlorophylls and carotenoids content was generally not significantly

349 affected by Pi deficiency [see Supporting Information Table S2]. A decrease in $\mathrm{P}_{\mathrm{N}}$ intensity after

3503 weeks of culture was accompanied by soluble sugar accumulation in shoots of all the oat

351 cultivars studied (the highest for cv. Rajtar - 1.9 times higher in comparison to +P) (Fig. 3 D-E).

352 Soluble sugar content in the roots of -P plants was similar to control. Phosphate deficiency led to

353 starch accumulation both in shoots (up to 1.8 times higher for cv. Krezus) and roots (1.3 times

354 higher for all cultivars) of -P plants (Fig. 3 F-G). Sugar content in PA plants was in general 
355

356

357

358

359

360

361

362

363

364

365

366

367

368

369

370

371

372

373

374

375

376

377

378

379

380

381

382

383

384

385

similar to control, however, an increase in soluble sugars was observed for cv. Arab shoots and cv. Szakal roots (Fig. 3 D-E).

Organic acids $/ \mathrm{H}^{+}$releases of oat roots were estimated using an agar sheet with $\mathrm{pH}$ indicator (bromocresol purple). There was no rhizosphere acidification, irrespectively of phosphate treatment, and even alkalization was observed [see Supporting Information Fig. S3].

Phosphate deficiency markedly increased acid phosphatase secretion and activity, which was visualized by an in vivo method (Fig. 4). The darkest red-brown colour indicating APase activity was observed in -P plant roots. APase tissue localization showed the highest activity in vascular tissues and in root epidermis of -P plants (Fig. 4N-O).

Phosphate deficiency led to enhanced extracellular APase activity in the roots of all the studied cultivars (Fig. 5A-C). APase activity was significantly higher already after one week of culture on -P medium in comparison to control (2.8 times higher for cv. Krezus and about 2 times higher for cv. Rajtar and Szakal). The highest activity was observed in cv. Krezus after 3 weeks of culture (7 times higher than $+\mathrm{P}$ ). Plants grown on PA medium showed similar APase activity to control (Fig. 5A-C). Extracellular APase activity exhibited a high negative correlation with tissue Pi content. Kinetic assay of extracellular APase activity showed at least 2 times higher Vmax value for $-\mathrm{P}$ plants of all the tested plant cultivars, as compared to control (and even 3 times higher for cv. Krezus and Szakal) [see Supporting Information Fig. S4]. The Michaelis constant $\left(\mathrm{K}_{\mathrm{m}}\right)$ was markedly lower only for cv. Krezus and Rajtar -P plants. PA plants had similar $\mathrm{V}_{\max }$ and $\mathrm{K}_{\mathrm{m}}$ values compared to control plants [see Supporting Information Fig. S4].

Insufficient phosphate supply did not cause such a significant increase in intracellular phosphatase activity (Fig. 5D-I) like extracellular enzymes. APase activity in -P plant shoots was increased only for cv. Krezus after one week of culture (1.6 times higher than in control) (Fig. 5D-F). After 2 weeks of -P culture, a higher increase of APase activity was observed in cv. Rajtar (2 times higher than in $+\mathrm{P}$ ) and cv. Szakal (3.5 higher) shoots. After 3 weeks of -P culture, an increase in enzyme activity was observed only for shoots of cv. Krezus, whereas a decrease in the shoots was recorded in cv. Rajtar and Szakal (down to $50 \%$ of control). APase activity in the shoots of PA plants was similar to control during two weeks of culture and decreased only after 3 weeks in cv. Rajtar and Szakal (78\% and 52\% of control, respectively) (Fig. 5D-F).

APase activity in the roots of plants grown on -P medium for 1-2 weeks was similar to control for all the studied oat cultivars, except cv. Krezus, where the activity was 1.5-2 times 
386 higher than in control plants and cv. Rajtar where the activity was reduced down to $44 \%$ in 387 comparison to + P plants (Fig. 5G-I). The highest increase in this enzyme activity was observed in

388

389

390

391

392

393

394

395

396

397

398

399

400

401

402

403

404

405

406

407

408

409

410

411

412

413

414

415

416

cv. Szakal after 3 weeks of -P culture (6 times higher than in control), whereas only a 1.7 times

increase was observed for cv. Krezus and Rajtar. Plants grown on medium with phytate showed similar activity of root APase compared to control (Fig. 5G-I).

Three main APase isoforms (about $95 \mathrm{kDa}, 70 \mathrm{kDa}$ and $27 \mathrm{kDa}$ ) were detected in native electrophoresis gels, independently of phosphorus treatment, however, the activity of the smallest one was higher in roots than in shoots, especially in -P and PA plants (except cv. Szakal) (Fig. 6).

The effect of mycorrhizal colonization (м) on growth parameters and Pi content in two selected oat cultivars (Arab and Krezus) was also investigated. Shoot height of both oat cv. was neither affected by phosphate nutrition nor by AM fungus (Table 2). The longest roots were observed in PA and $\mathrm{PA}_{\mathrm{M}}$ plants of both oat cultivars (about 1.4 times longer than in control). Shoot fresh and dry weight was 2 times lower in $-\mathrm{P}$ (both cultivars) and $-\mathrm{P}_{\mathrm{M}}$ plants (only cv. Arab) (Table 2). Mycorrhization increased shoot mass 1.7 times in comparison to non-infected plants grown on phytate medium and without phosphate only in cv. Krezus. Root fresh weight was 1.4 times higher in $-\mathrm{P}$ plants (cv. Arab) and 2.5 higher in $\mathrm{PA}_{\mathrm{M}}$ plants (cv. Krezus). Mycorrhization increased root mass only in $\mathrm{PA}_{\mathrm{M}}$ plants (1.6 higher than in PA plants) in cv. Krezus (Table 2).

Phosphate deficiency decreased Pi content in shoots, irrespectively of mycorrhizal colonization (Fig. 7A). A higher decrease (down to 11-14\% of control) was observed in cv. Arab shoots than in Krezus (down to 21-24\%). PA plants also showed a decreased Pi content in the shoots (44\% and 29\% for cv. Arab and Krezus, respectively). Mycorrhizal infection led to a decrease in Pi content (down to 68\% of control) in the shoots of cv. Krezus plants grown on phytic acid when compared to $+\mathrm{P}$ plants. However, mycorrhization resulted in a higher Pi content in $\mathrm{PA}_{\mathrm{M}}$ plants (1.8 times higher and 2.4 higher for cv. Arab and Krezus, respectively) in comparison to non-infected plants (PA) (Fig. 7A-D). Pi content in oat roots grown on phytic acid and without phosphate decreased (irrespective of mycorrhiza), however, Pi content was lower in -P plants than in PA plants. The positive effect of mycorrhization was observed only in $-\mathrm{P}_{\mathrm{M}}$ plants of cv. Arab (1.8 times higher Pi content in comparison to -P plants) (Fig. 7C). 


\section{Discussion}

418

419

420

421

422

423

424

425

426

427

428

429

430

431

432

433

434

435

436

437

438

439

440

441

442

443

444

445

446

Understanding plant responses to low phosphate nutrition has been the subject of considerable research efforts for many decades. Recently, molecular mechanisms of model plant (mainly $A$. thaliana, but also $O$. sativa) responses to Pi deficiency have been intensively studied, whereas acclimation mechanisms of crop plants, like oat (A. sativa) to low-Pi stress remain poor known. Oat plants are usually grown on low-productive, poor soils with Pi shortage (Butt et al. 2008), however, their responses to Pi starvation are rarely investigated. The present study contributes to the understanding of oat acclimation mechanisms to low Pi nutrition. Our results indicated that acid phosphatases play the most important role in oat acclimation to Pi deficiency, mainly extracellular enzymes involved in Pi acquisition. The study showed that four different oat cultivars could effectively utilized phytates, organic P forms. Phytates are generally not an easily available P form for other cultivated crop plants (George et al. 2008; Richardson et al. 2009). Studied oat cultivars developed similar acclimation mechanisms to Pi deficiency, however, there were differences in the usage of shoot/root or internal/extracellular APases pools.

Pi deficiency in nutrient media caused severe Pi content decrease in plant tissues (down to $4 \%$ of control after three weeks of culture). Surprisingly, all the studied oat cultivars (Arab, Krezus, Rajtar, Szakal) grown with phytic acid showed similar P content (which only slightly decreased after three weeks of culture) to the plants supplied with easily accessible inorganic $\mathrm{P}$ (Fig. 1, Fig. S1). These results suggest that such organic $\mathrm{P}$ is a potentially available source of $\mathrm{P}$ for oat plants. Similar effects were also observed for barley plants in our previous study (Ciereszko et al. 2011) and in another study on rapeseed (Zhang et al. 2010). However, the ability of utilizing organic $\mathrm{P}$ is not very common in plants. For example, Pi content in shoots of wheat plants grown on organic source of $\mathrm{P}$ was about three times lower as compared to control in the study of George et al. (2008), whereas in our study, some PA plants showed even higher Pt content [see Supporting Information Fig. S1].

Pi acquisition by plants may be enhanced due to root morphological/architectural adaptations that increase the root surface area. The studied oat cultivars grown on -P medium showed significantly decreased shoot weight and height (Fig. 2), whereas root length was hardly affected by Pi deficiency and even root elongation was observed for A. sativa cv. Arab (associated with smaller root diameter); the growth of PA plants was similar to control (Table 1). 
447 The ability to maintain, or even extend, root growth is one of the important strategies to improve

448 Pi uptake efficiency. Our results showed a pronounced increase in root/shoot biomass (and

449 length) ratio for the four studied oat cultivars under low Pi supply [see Supporting Information

450 Fig. S2], which corresponded with low P concentration in the tissues. However, root

451 architectural response may vary between plant species and even genotypes, as indicated in other

452 reports (Péret et al. 2014 and articles cited therein). Some plants tend to reduce primary root

453 growth and extend lateral root and root hair (e.g. A. thaliana), whereas other increase both

454 primary and lateral root growth (e.g. O. sativa) (Chevalier et al. 2003; Dai et al. 2012; Péret et

455 al. 2014; Hoehenwarter et al. 2016) or increase primary root growth and reduce lateral root

456 formation (e.g. in maize, Li et al. 2012). Among the studied oat cultivars, Pi deficiency had the

457 lowest impact on the growth of oat cv. Arab (Table 1). It has been reported that plants growing in

458 Pi-deficient conditions often allocate more assimilates to root growth and tend to have fine roots

459 (of small diameter), and therefore a large surface area. However, in our experimental conditions

460 we did not observe larger root surface areas (except for cv. Krezus). Moreover, calculated areas

461 were even lower for oat cv. Rajtar and Szakal (Table 1, S1). We have previously investigated the

462 growth of bean, barley, cucumber, oat and wheat plants under Pi-deficient conditions, where the

463 reduction of shoot mass was usually accompanied by root elongation stimulation and a

464 significant increase of the root/shoot weight ratio (Ciereszko et al. 1999; 2002; 2011 a,b;

465 Żebrowska et al. 2012). However, in spite of the currently available data, genetic control of

466 primary and lateral root development in monocot/cereal species under Pi deficiency remains

467 poorly understood (Li et al. 2012; Péret et al. 2014). Recent quantitative trait loci analyses in

468 wheat or other cereals have shown that Pi utilization efficiency is a complex, polygenic trait

469 (Aziz et al. 2014).

470

Pi deficiency markedly decreased growth rate parameters, especially for cv. Krezus and

471 to a lesser extend for cv. Rajtar and Szakal. In contrast, unit leaf rate and relative growth rate of

$472 \mathrm{cv}$. Arab was even higher, as compared to control (Table 1) [see also Supporting Information

473 Table S1]. However, culture on PA media not affected growth parameters of studied oat plants.

474 High RGR values are usually observed in plants grown under optimal conditions (Shipley and

475 Keddy 1988). Therefore, an increase of this parameter observed in -P oat plants (cv. Arab) could

476 indicate that these plants are less susceptible to Pi deficiency. Similar results were obtained for

477 potato genotypes grown under Pi deficiency, where high RGR values were associated with 
478 higher P-utilization efficiency (Balemi and Schenk 2009). Furthermore, Pi-deficient legumes

479 with high RGR rates (Lotus australis) showed both morphological and physiological (i.e. root 480 carboxylate dynamics) root adaptations, whereas plants with lower RGR (i.e. Cullen cinereum) 481 demonstrated only morphological root adaptations (Suriyagoda et al. 2012). Recent studies 482 suggested that differences in P-use efficiency between two contrasting wheat genotypes resulted 483 from different Pi and organic P allocation patterns. Shoot biomass production in both cultivars 484 was surprisingly similar, irrespectively of P supply, whereas Pi efficient genotype showed higher 485 root biomass (Aziz et al. 2014).

The decrease in biomass and growth rate indicators under Pi starvation could be caused by limited PAR absorption (due to the smaller leaf area and their number) or less efficient use of absorbed radiation; therefore, photosynthetic intensity was measured. A significant decline (down to $60 \%$ of control) of $\mathrm{P}_{\mathrm{N}}$ occurred in leaves of all studied oat cultivars after 3 weeks of growth on Pi deficient medium (Fig. 3), however, photosynthetic pigments concentration was not affected [see Supporting Information Table S2]. In contrast, $\mathrm{P}_{\mathrm{N}}$ of PA plants was similar to control, which indicated that Pi acquired from phytate was effectively used for oat plants metabolism. Early and intermediate Pi deficiency usually has no influence on photosynthetic $\mathrm{CO}_{2}$ exchange, or may lead to increased photosynthetic intensity, however, severe Pi deficiency leads to a decline in $\mathrm{P}_{\mathrm{N}}$, as observed in previous studies (Ciereszko et al. 1996; Maleszewski et al. 2004; Li et al. 2006). Interestingly, high photosynthetic activity under Pi deficiency could be obtained as a result of phospholipid replacement with galactolipids and sulfolipids during leaf development, as observed in Proteaceae species (Lambers et al. 2012), similar replacements of lipid components in plasma membranes were also reported for oat plants (Andersson et al. 2005). Changes in photosynthetic activity in Pi-deficient plants often cause redistribution of assimilates. The accumulation of soluble sugars and starch in leaves and starch in roots was demonstrated in P oat cultivars (Fig. 3 D-G). The observed differences in sugar contents could be both the result of sugar metabolism modification and/or changes in sugar distribution between plant organs. High sugar content in roots of Pi-deficient plants may be caused by increased assimilate transport to these organs, and enhanced activity of sucrose hydrolysing enzymes, as previously observed for bean (Ciereszko et al. 1996; 1999; Ciereszko and Barbachowska 2000). Pi depletion changed the expression of many genes involved in biosynthesis and degradation of starch and sucrose, and caused starch and sugar accumulation in Arabidopsis and rice leaves (Ciereszko and 
509 Kleczkowski 2005; Misson et al. 2005; Hammond and White 2008; Park et al. 2012). Moreover, 510 sucrose transport modification in the phloem, observed under Pi deficiency, might also initiate 511 sugar signalling cascades that alter multiple gene expression involved in plant response to Pi 512 deficiency (Hammond and White 2008; Park et al. 2012).

513 Pi use efficiency is possible due to Pi remobilization from various cell compartments 514 (mainly vacuole) and from older to younger plant organs by internal acid phosphatases (Duff et 515 al. 1994; Tian and Liao 2015). Pi deficiency affected the intracellular APase activity in roots 516 and shoots of oat plants, however, these changes were not as significant as in case of 517 extracellular APases (Fig. 5). Generally, higher APase activity in shoots was observed only for 518 oat cv. Krezus and in roots of three oat cultivars (except cv. Arab) (Fig. 5D-I). APase enzyme 519 activities in the plants grown on PA nutrient media were similar to control values. Three APase 520 isoforms were found in shoot and root extracts of all the studied oat cultivars. The smallest 521 isoform was strongly expressed in roots, generally irrespectively of P treatment (Fig. 6). No 522 significant differences in isoform patterns between oat cultivars under study were observed, 523 similar to our previous results (Ciereszko et al. 2011b, Żebrowska et al. 2012).

524 The increased Pi uptake capacity of roots is dependent not only on the increased nutrient 525 absorption surface, but also on the metabolic capacity to release a wide range of organic anions, 526 protons (or enzymes) to the ground, which play a key role in increasing the mobilization of $\mathrm{P}$ 527 from sparingly soluble sources in soil (Wang et al. 2015, 2017; Tian and Liao 2015 and articles 528 cited therein). However, our measurements did not show a distinct effect of the insufficient Pi 529 feeding on rhizosphere acidification (due to organic acid or $\mathrm{H}^{+}$release) [see Supporting 530 Information Fig. S3], which indicated that oat cultivars rather did not respond to Pi starvation by 531 increased protons or organic acid release from the root system (rhizoplane), at least in those 532 experimental conditions. Recent studies conducted on different crops, including oat, showed that 533 organic anion exudation to the rhizosphere played a minor role in improving Pi availability and 534 uptake in agricultural soils (Wang et al. 2015; 2016). The latter authors indicated that other 535 factors, such as root morphology, $\mathrm{pH}$ (associated with $\mathrm{H}^{+}$release by the roots) or acid 536 phosphatases might play a key role in the effective utilization of phosphorus (Wang et al. 2015; 537 2016). 

soil volume by extending fungi hyphae beyond P-depletion zone in the soil (Smith and Smith 2011; Yang et al. 2012; Ceasar et al. 2014). As an example, foxtail millet plants inoculated with

\section{1}

542 Glomus mosseae showed about 30\% increase in seed yield when compared to non-infected plants (Ceasar et al. 2014). In our study, no significant positive effect of mycorrhization on plant growth was observed - only cv. Krezus plants grown on phytic acid showed almost 2 times higher shoot mass when compared to non-infected plants (Table 2). Consistent with that result, shoot Pi content in this cultivar was also increased (Fig. 7), which indicated that colonization by AM fungi increased plant acquisition of organic $\mathrm{P}$ forms. This was consistent with previous results, also obtained in oat plants, especially after dual inoculation with Glomus etunicatum and Glomus intraradices (Joner et al. 2000; Khan et al. 2003). Phytate utilization was also enhanced in trifoliate orange (Poncirus trifoliata) inoculated with AM fungi (due to the increased phytase and APase activity in the roots and substrate (Shu et al. 2014). Interestingly, some studies showed a negative influence of mycorrhization on host plant growth, as a result of sink competition for photosynthates or pairing of host and fungal symbiont (Rai et al. 2013; Nouri et al. 2014 and articles cited therein). In contrast, wheat plants inoculated with AM fungi had higher biomass and grain yield, regardless of $\mathrm{P}$ application (Hu et al. 2010).

Enzyme secretion by plant roots (or rhizosphere microorganisms) may also increase Pi uptake from organic phosphorus sources in the soil. The increase of APases activity and secretion seems to be a common reaction to Pi deficiency and was reported in many works, also in our previous studies conducted on barley and wheat (Ciereszko et al. $2011 \mathrm{a}, \mathrm{b}$ ). The increase in extracellular APase activity was already observed after one week of growth in -P medium (Fig. 5), which indicated that enzyme secretion from the roots is an early plant response to Pi deficiency. High APase activity in the root epidermis of phosphate-depleted plants observed in root transverse sections (Fig. 4) indicated that these enzymes could be secreted by oat roots to the ground. Our previous study conducted on whole roots of -P oat showed high APase activity not only in roots, but also within a few millimetres from plant roots (Żebrowska et al. 2012), what suggested for increased production and secretion of enzymes by these roots under Pi deficiency. White lupine roots also showed the highest APase activity in root epidermis and root hairs of both proteoid and non-proteoid roots (Wasaki et al. 2009; Tang et al. 2013). It seems that the production of APases associated with the root surface (rather than those released to the 
569 rhizosphere) is a better strategy to efficiently acquire Pi liberated from organic P. Recent studies

570 have indicated that purple APases secreted by $A$. thaliana under Pi deficiency remains associated 571 with the surface of root epidermal cells (AtPAP10) or cell wall-targeted (AtPAP25) and play an

572 important role in plant acclimation to Pi deficiency (Wang et al. 2011; Del Vecchio et al. 2014).

573 The highest extracellular acid phosphatase activity was observed after 3-week culture of

574 oat cv. Krezus, when compared to other cultivars (Fig. 5A-C). Oat genotypes with high

575 efficiency of extracellular APase activity or enzyme secretion from the roots to the soil could

576 probably significantly enhance the availability of phosphorus from organic fertilizers. Our study

577 demonstrated that all oat cultivars can use phytate as the sole source of phosphorus and can grow

578 and develop well in such conditions, in contrast to other plants (George et al. 2008). The highest

579 extracellular APase activity was observed in younger, growing parts of the roots. Tang et al.

580 (2013) also showed the induction of APase activity in the elongation zone of the root tips and

581 root meristems of lupin. A significant increase in APase production and secretion under Pi

582 deficiency is well documented in numerous plants (Żebrowska and Ciereszko 2009; Tran et al.

5832010 and articles cited therein). It was shown that the overexpression of gene(s) encoding APase

584 in plant roots (including root hairs) increased Pi efficiency, when compared to control (Wasaki et

585 al. 2009; Zhang et al. 2014; Lu et al. 2016). Interestingly, the high APase and phytase activity

586 along with fine root morphology of Polygonum hydropiper (mining ecotype) are responsible for

587 organic phosphorus assimilation capacity and, as suggested, may be used in phytoremediation of

588 areas polluted with organic P (Ye et al. 2015). However, some authors reported no relationship

589 or a negative relationship between acid phosphatase activity and Pi use efficiency, e.g. clover

590 genotypes with contrasting Pi-uptake efficiency did not differ in APase activity (Hunter and

591 McManus 1999; Yan et al. 2001). What is more, there is no evidence that the expression of up-

592 regulated phosphatase genes under Pi deficiency is higher in P-efficient rice genotypes (Rose et

593 al. 2013). Additionally, the differences in APase activities observed in laboratory conditions are

594 not that evident when plants are grown in the soil (George et al. 2008). Therefore, the detailed

595 function of APases in the acclimation of various crop plants to Pi deficiency is still not well

596 understood and is under intensive investigations. A more detailed analysis of APases/phytases

597 secreted by oat roots is necessary. In a recent study, the function of a novel secreted rice purple

598 APase, OsPAP10c, was investigated in the utilization of external organic P (Lu et al. 2016). It

599 was demonstrated that the overexpression of $O S P A P 10 c$ significantly increased APase activity in 
600 rice tissues, mainly on the root surface, but also in culture media. Other recent studies indicated 601 that the concentration of rhizosphere APases was positively correlated with plant-available 602 phosphorus fractions and Pi absorption (including Brassica napus and A. sativa) in Pi-deficient 603 soils (Wang et al. 2016).

604 Conclusion

605 In conclusion, the studied oat cultivars grew well both on the medium containing 606 inorganic $\mathrm{P}$ as well as organic $\mathrm{P}$ (phytate), and only slightly differed in terms of acclimation to 607 moderate Pi deficiency. Pi sources are non-renewable and organic P compounds are usually in 608 excess. Therefore, it is currently important to investigate and select cereal plant genotypes 609 tolerant to Pi depletion in the soil, which are able to develop in a phytate-rich ground in order to 610 sustain the yield of common crops. The study provided useful information for future 611 investigation of oat behaviour under field conditions. Generally, small variations in secretion, 612 localization and activity of APases were observed between oat cultivars; however, in certain 613 conditions they used different pools of acid phosphatases to acquire Pi from external or internal 614 P sources. The most important component of the acclimation mechanism of oat to low Pi 615 conditions was the enhanced activity of mainly extracellular acid phosphatases.

616

617 Abbreviations

618

619 APase Acid phosphatase

620 LAR Leaf area ratio

621 P Phosphorus

622 PA Plants cultured on medium with phytate

623 PAGE Polyacrylamide gel electrophoresis

$624 \mathbf{P A}_{\mathbf{M}}$ Oat plants cultured on medium with phytate inoculated with Glomus intraradices

625 Pi Inorganic phosphate

$626 \mathbf{P}_{\mathbf{N}}$ Net photosynthesis intensity

$627 \mathrm{Pt}$ Total phosphorus

$628+\mathbf{P}$ plants Phosphate-sufficient plants (control)

$629+\mathbf{P}_{\mathbf{M}}$ Phosphate-sufficient oat plants inoculated with Glomus intraradices 
630 -P plants Phosphate-deficient plants

$631-\mathbf{P}_{\mathbf{M}}$ Phosphate-deficient oat plants inoculated with Glomus intraradices

632 RGR Relative growth rate

633 SWR Stem weight ratio

634 ULR Unit leaf rate

635

636 Acknowledgements

637 We wish to thank the cereal seeds producers IHAR (Strzelce, Poland) and DANKO (Choryn, 638 Poland) for oat seeds used in the experiments. We thank for technical assistance by Magdalena 639 Klimiuk, Beata Kuciejczyk (growth and productivity parameters measurements), and Martyna 640 Kempista, Paula Trebicka (photosynthesis and sugar estimations).

641

642

643

644

645

646

647

648

649

650

651

652

653

654

655

\section{References}

Amtmann A, Armengaud P. 2009. Effects of N, P, K and S on metabolism: new knowledge gained from multi-level analysis. Current Opinion in Plant Biology 12:275 - 283.

Andersson MX, Larsson KE, Tjellstrom H, Liljenberg C, Sandelius AS. 2005. Phosphate-limited oat. The plasma membrane and the tonoplast as major targets for phospholipid to glycolipid replacement and stimulation of phospholipases in the plasma membrane. The Journal of Biological Chemistry 280:27578 - 27586.

Aziz T, Finnegan PM, Lambers H, Jost R. 2014. Organ-specific phosphorus-allocation patterns and transcript profiles linked to phosphorus efficiency in two contrasting wheat genotypes. Plant Cell and Environment 37:943 - 960.

Baker A, Ceasar SA, Palmer AJ, Paterson JB, Qi W, Stephen P. Muench SP, Baldwin SA. 2015. Replace, reuse, recycle: improving the sustainable use of phosphorus by plants. Journal of Experimental Botany 66:3523 - 3540. 
656 Balemi T, Schenk M. 2009. Genotypic variation of potato for phosphorus efficiency and 657 quantification of phosphorus uptake with respect to root characteristics. Journal of Plant $658 \quad$ Nutrition and Soil Science 172:669 - 677.

659 Bradford MM. 1976. A rapid and sensitive method for the quantitation of microgram quantities 660 of protein utilizing the principle of protein-dye binding. Analytical Biochemistry 72:248 661254.

662

663

664

665

666

667

668

669

670

671

672

673

674

675

676

677

678

679

680

681

Butt MS, Tahir-Nadeem M, Khan MKI, Shabir R, Butt MS. 2008. Oat: unique among the cereals. European Journal of Nutrition 47: 68 - 79.

Ceasar SA, Hodge A, Baker A, Baldwin SA. 2014. Phosphate concentration and arbuscular mycorrhizal colonisation influence the growth, yield and expression of twelve PHT1 family phosphate transporters in foxtail millet (Setaria italica). PLoS ONE 9 (9): e108459.

Chevalier F, Pata M, Nacry P, Doumas P, Rossignol M. 2003. Effects of phosphate availability on the root system architecture: large-scale analysis of the natural variation between Arabidopsis accessions. Plant and Cell Environment 26:1839-1850.

Ciereszko I, Barbachowska A. 2000. Sucrose metabolism in leaves and roots of bean (Phaseolus vulgaris L.) during phosphate deficiency. Journal of Plant Physiology 156:640 - 644.

Ciereszko I, Gniazdowska A, Mikulska M, Rychter AM. 1996. Assimilate translocation in bean plants (Phaseolus vulgaris L.) during phosphate deficiency. Journal of Plant Physiology 149:343 - 348.

Ciereszko I, Janonis A, Kociakowska M. 2002. Growth and metabolism of cucumber in phosphate-deficient conditions. Journal of Plant Nutrition 25:1115 - 1127.

Ciereszko I, Kleczkowski LA. 2005. Expression of several genes involved in sucrose/starch metabolism as affected by different strategies to induce phosphate deficiency in Arabidopsis. Acta Physiologiae Plantarum 27:147 - 155.

Ciereszko I, Miłosek I, Rychter AM. 1999. Assimilate distribution in bean plants (Phaseolus vulgaris L.) during phosphate limitation. Acta Societatis Botanicorum Poloniae 68:1 - 5. 
682 Ciereszko I, Szczygła A, Żebrowska E. 2011 a. Phosphate deficiency affects acid phosphatases 683 activity and growth of two wheat varieties. Journal of Plant Nutrition 34:815 - 829.

684 Ciereszko I, Żebrowska E, Ruminowicz M. 2011 b. Acid phosphatases and growth of barley 685 (Hordeum vulgare L.) cultivars under diverse phosphorus nutrition. Acta Physiologiae $686 \quad$ Plantarum 33: 2355 - 2368.

687 Cordell D, Drangert J-O, White S. 2009. The story of phosphorus: global food security and food 688

Dai X, Wang Y, Yang A, Zhang WH. 2012. OsMYB2P-1, an R2R3 MYB transcription factor, is involved in the regulation of phosphate-starvation responses and root architecture in rice.

692 Plant Physiology 159:169 - 183.

Del Vecchio HA, Ying S, Park J, Knowles VL, Kanno S, Tanoi K, She Y-M, Plaxton WC. 2014. 693 The cell wall-targeted purple acid phosphatase AtPAP25 is critical for acclimation of

695 696

697

698

699

700

701

702

703

704

705

706

707 Arabidopsis thaliana to nutritional phosphorus deprivation. Plant Journal 80:569 - 581.

Duff SM, Sarath G, Plaxton WC. 1994. The role of acid phosphatases in plant phosphorus metabolism. Plant Physiology 90:791 - 800.

Faucon M-P, Houben D, Reynoird J-P, Mercadal-Dulaurent A-M, Armand R, Lambers H. 2015. Advances and perspectives to improve the phosphorus availability in cropping systems for agroecological phosphorus management. Advances in Agronomy 134:1 - 29.

George TS, Gregory PJ, Hocking PJ, Richardson AE. 2008. Variation in root associated phosphatase activities in wheat contributes to the utilization of organic P substrates in-vitro, but does not explain differences in the P-nutrition when grown in soils. Environmental and Experimental Botany 64:239 - 249.

Gerke J. 2015. Phytate (inositol hexakisphosphate) in soil and phosphate acquisition from inositol phosphates by higher plants. Plants 4:253 - 266.

Hammond JP, Broadley MR, White PJ. 2004. Genetic responses to phosphorus deficiency. Annals of Botany 94:323 - 332. 
708

709

710

711

712

713

714

715

716

717

718

719

720

721

722

723

724

725

726

727

728

729

730

731

732

733

734

Hammond JP, White PJ. 2008. Sucrose transport in the phloem: integrating root responses to phosphorus starvation. Journal of Experimental Botany 59:93 - 109.

Hermans C, Hammond JP, White PJ, Verbruggen N. 2006. How do plants respond to nutrient shortage by biomass allocation? Trends in Plant Sciences 11:610 - 617.

Hoehenwarter W, Mönchgesang S, Neumann S, Majovsky P, Abel S, Müller J. 2016. Comparative expression profiling reveals a role of the root apoplast in local phosphate response. BMC Plant Biology 16:106.

Holford ICR. 1997 Soil phosphorus: its measurement, and its uptake by plants. Australian Journal of Soil Research 35:227 - 240.

Hu J, Lin X, Wang J, Cui X, Dai J, Chu H, Zhang J. 2010. Arbuscular mycorrhizal fungus enhances $\mathrm{P}$ acquisition of wheat (Triticum aestivum L.) in a sandy loam soil with long-term inorganic fertilization regime. Applied Microbiology and Biotechnology 88:781 - 787.

Hunter DA, McManus MT. 1999. Comparison of acid phosphatases in two genotypes of white clover with different responses to applied phosphate. Journal of Plant Nutrition 22:679 692.

Joner EJ, van Aaerle IM, Vosatka M. 2000. Phosphatase activity of extra-radical arbuscular mycorrhizal hyphae: a review. Plant and Soil 226:199 - 210.

Karandashov V, Bucher M. 2005. Symbiotic phosphate transport in arbuscular mycorrhizas. Trends in Plant Sciences 10:22 - 29.

Khan IA, Ahmad S, Ayub N. 2003. Response of oat (Avena sativa) to inoculation with vesicular arbuscular mycorrhizae (VAM) in the presence of phosphorus. Asian Journal of Plant Sciences 2:368 - 370 .

Lambers H, Cawthray GR, Giavalisco P, Kuo J, Laliberté E, Pearse SJ, Scheible W-R, Stitt M, Teste F, Turner BL. 2012. Proteaceae from severely phosphorus-impoverished soils extensively replace phospholipids with galactolipids and sulfolipids during leaf development to achieve a high photosynthetic phosphorus-use-efficiency. New Phytologist 196:1098 1108. 
735

Lambers H, Finnegan PM, Jost R, Plaxton WC, Shane MW, Stitt M. 2015. Phosphorus nutrition in Proteaceae and beyond. Nature Plants 1: 15109.

Li YF, Luo AC, Hassan MJ, Wei XH. 2006. Effect of phosphorus deficiency on leaf photosynthesis and carbohydrates partitioning in two rice genotypes with contrasting low phosphorus susceptibility. Rice Science 13:283 - 290.

Li Z, Xu C, Li K, Yan S, Qu X, Zhang J. 2012. Phosphate starvation of maize inhibits lateral root formation and alters gene expression in the lateral root primordium zone. BMC Plant Biology 12:89.

Lu L, Qiu W, Gao W, Tyerman SD, Shou H, Wang C. 2016. OsPAP10c, a novel secreted acid phosphatase in rice, plays an important role in the utilization of external organic phosphorus. Plant Cell and Environment 39:2247 - 2259.

Lynch JP. 2011. Root phenes for enhanced soil exploration and phosphorus acquisition: tools for future crops. Plant Physiology 156:1041 - 1049.

Maleszewski S, Ciereszko I, Skowrońska A, Mieczejko E, Kozłowska-Szerenos B. 2004. Changes induced by low oxygen concentration in photosynthetic and respiratory $\mathrm{CO}_{2}$ exchange in phosphate-deficient bean leaves. Biologia Plantarum 48:401 - 405.

Miranda D, Fischer G, Ulrichs C. 2011. The influence of arbuscular mycorrhizal colonization on the growth parameters of cape gooseberry (Physalis peruviana L.) plants grown in a saline soil. Journal of Soil Sciences and Plant Nutrition 11:18 -31.

Misson J, Raghothama KG, Jain A, Jouhet J, Block MA, Bligny R, Ortet P, Creff A, Somerville S, Rolland N, Doumas P, Nacry P, Herrerra-Estrella L, Nussaume L, Thibaud MC. 2005. A genome-wide transcriptional analysis using Arabidopsis thaliana Affymetrix gene chips determined plant responses to phosphate deprivation. Proceedings of the National Academy of Sciences of the United States of America. 102:11934 -11939.

Neumann G, Massonneau A, Langlade N, Dinkelaker B, Hengeler C, Romheld V, Martinoia E. 2000. Physiological aspects of cluster root function and development in phosphorus-deficient white lupin (Lupinus albus L.). Annals of Botany 85:909 -919. 
762 Niu YF, Chai RS, Jin GL, Wang H, Tang CX, Zhang YS. 2013. Responses of root architecture 763 development to low phosphorus availability: a review. Annals of Botany 112:391 - 408.

764 Nouri E, Breuillin-Sessoms F, Feller U, Reinhardt D. 2014. Phosphorus and nitrogen regulate 765 arbuscular mycorrhizal symbiosis in Petunia hybrida. PLoS ONE 9(3): e90841.

766

767

Nowak J. 2009. Effects of mycorrhization and phosphorus nutrition on nutrient uptake, growth and flowering of china aster (Callistephus chinensis (L.) Nees) cultivated on ebb-and-flow benches. Acta Agrobotanica 62:77 - 81.

Olczak M, Morawiecka B, Wątorek W. 2003. Plant purple acid phosphatases - genes, structures and biological function. Acta Biochimica Poloniae 50:1245 - 1256.

Park MR, Baek SH, de Los Reyes BG, Yun SJ, Hasenstein KH. 2012. Transcriptome profiling characterizes phosphate deficiency effects on carbohydrate metabolism in rice leaves. Journal of Plant Physiology 169:193 - 205.

Péret B, Desnos T., Jost R, Kanno S, Berkowitz O, Nussaume L. 2014. Root architecture responses: in search of phosphate. Plant Physiology 166:1713 -1723.

Phillips J, Hayman D. 1970. Improved procedures for clearing roots and staining parasitic and vesicular-arbuscular mycorrhizal fungi for rapid assessment of infection. Transactions of the British Mycological Society 55:157 - 160.

Plaxton WC, Tran HT. 2011. Metabolic adaptations of phosphate-starved plants. Plant Physiology 156:1006 - 1015.

Raghothama KG, Karthikeyan AS. 2005. Phosphate acquisition. Plant and Soil 274: 37 - 49.

Rai A, Rai S, Rakshit A. 2013. Mycorrhiza-mediated phosphorus use efficiency in plants. Environmental Experimental Botany 11:107 - 117.

Richardson AE, Hocking PJ, Simpson RJ, George TS. 2009. Plant mechanisms to optimise access to soil phosphorus. Crop and Pasture Science 60:124 - 143.

Rose TJ, Impa SM, Rose MT, Pariasca-Tanaka J, Mori A,Heuer S, Johnson-Beebout SE, Wissuwa M. 2013. Enhancing phosphorus and zinc acquisition efficiency in rice: a critical 
788 789

790

791

792

793

794

795

796

797

798

799

800

801

802

803

804

805

806

807

808

809

810

811

812

813

review of root traits and their potential utility in rice breeding. Annals of Botany 112:331 345.

Rychter AM, Rao IM. 2005. Role of phosphorus in photosynthetic carbon metabolism In: Pessarakli M (ed) Handbook of Photosynthesis. 2nd Edition, CRC Press Taylor \& Francis Group, Boca Raton, 137-162.

Schachtman DP, Reid RJ, Ayling SM. 1998. Phosphorus uptake by plants: from soil to cell. Plant Physiology 116:447 - 453.

Scholz RW, Roy AH, Hellums DT. 2014. Sustainable phosphorus management: a transdisciplinary challenge. In: Scholz et al. (eds.), Sustainable Phosphorus Management. Springer Science+Business Media Dordrecht 1-113.

Shenoy VV, Kalagudi GM. 2005. Enhancing plant phosphorus use efficiency for sustainable cropping. Biotechnology Advances 23:501 - 513.

Shipley B, Keddy P. 1988. The relationship between relative growth rate and sensitivity to nutrient stress in twenty eight emergent macrophytes. Journal of Ecology 76:1101 - 1110.

Shu B, Wang P, Xia RX. 2014. Effects of mycorrhizal fungi on phytate-phosphorus utilization in trifoliate orange (Poncirus trifoliata L. Raf) seedlings. Acta Physiologiae Plantarum 36:1023 - 1032 .

Smith FW, Mudge SR, Rae AL, Glassop D. 2003. Phosphate transport in plants. Plant and Soil 248:71-83.

Smith SE, Smith FA. 2011. Roles of arbuscular mycorrhizas in plant nutrition and growth: new paradigms from cellular to ecosystem scales. Annual Review of Plant Biology 62:227 - 250.

Stetter MG, Martin Benz M. Ludewig U. 2017. Increased root hair density by loss of WRKY6 in Arabidopsis thaliana. PeerJ 5:e2891; DOI 10.7717/peerj.2891

Suriyagoda LDB, Ryan MH, Renton M, Lambers H. 2012. Adaptive shoot and root responses collectively enhance growth at optimum temperature and limited phosphorus supply of three herbaceous legume species. Annals of Botany 110:959 - 968. 
814 Tang H, Li X, Zu C, Zhang F, Shen J. 2013. Spatial distribution and expression of intracellular

815

816

817

818

819

820

821

822

823

824

825

826

827

828

829

830

831

832

833

834

835

836

837

838

839 and extracellular acid phosphatases of cluster roots at different developmental stages in white lupin. Journal of Plant Physiology 170:1243 - 1250.

Thibaud MC, Arrighi JF, Bayle V, Chiarenza S, Creff A, Bustos R, Paz-Ares J, Poirier Y, Nussaume L. 2010. Dissection of local and systemic transcriptional responses to phosphate starvation in Arabidopsis. The Plant Journal 64:775 - 789.

Tian J, Liao H. 2015. The role of intracellular and secreted purple acid phosphatases in plant phosphorus scavenging and recycling. In: Plaxton WC, Lambers H. (eds.) Annual Plant Reviews. Phosphorus Metabolism in Plants. John Wiley \& Sons, Inc: Hoboken NJ. 48: 265 287.

Tran HT, Hurley BA, Plaxton WC. 2010. Feeding hungry plants: the role of purple acid phosphatases in phosphate nutrition. Plant Science 179:14 - 27.

Vance CP, Uhde-Stone C, Allan DL. 2003. Phosphorus acquisition and use: critical adaptations by plants for securing a nonrenewable resource. New Phytologist 157:423 - 447.

Wang L, Li Z, Qian W, Guo W, Gao X, Huang L, Wang H, Zhu H, Wu JW, Wang D, Liu D. 2011. The Arabidopsis purple acid phosphatase AtPAP10 is predominantly associated with the root surface and plays an important role in plant tolerance to phosphate limitation. Plant Physiology 157:1283 - 1299.

Wang Y, Krogstad T, Clarke JL, Hallama M, Øgaard AF, Eich-Greatorex S, Kandeler E, Clarke N. 2016. Rhizosphere organic anions play a minor role in improving crop species' ability to take up residual phosphorus (P) in agricultural soils low in $\mathrm{P}$ availability. Frontiers in Plant Science 7:1664.

Wang Y-L, Almvik M, Clarke N, Eich-Greatorex S, Øgaard AF, Krogstad T, Lambers H, Clarke JL. 2015. Contrasting responses of root morphology and root-exuded organic acids to low phosphorus availability in three important food crops with divergent root traits. AoB PLANTS 7:plv097. 
840 Wang Y, Krogstad T, Clarke N, Øgaard AF, Clarke JL. 2017. Impact of phosphorus on

841 rhizosphere organic anions of wheat at different growth stages under field conditions. $A o B$

842 PLANTS 9:plx008

843 Wasaki J, Maruyama H, Tanaka M, Yamamura T, Dateki H, Shinamo T, Ito S, Osaki M. 2009.

844 Overexpression of LASAP2 gene for secretory acid phosphatase in white lupin improves the 845 phosphorus uptake and growth of tobacco plants. Soil Science and Plant Nutrition 55:107 846113.

847 Wellburn AR. 1994. The spectra determination of chlorophyll-a and chlorophyll-b, as total 848 carotenoids, using various solvents with spectrophotometers of different resolution. Journal 849 of Plant Physiology 144:307 - 313.

850 Williamson LC, Ribrioux SP, Fitter AH, Leyser HMO. Phosphate availability regulates root 851 system architecture in Arabidopsis. Plant Physiology 2001; 126: 875-882.

852 Wissuwa M. 2003. How do plants achieve tolerance to phosphorus deficiency? Small causes $853 \quad$ with big effects. Plant Physiology 133:1947 - 1958.

854 Yan X, Liao H, Trull MC, Beebe SE, Lynch JP. 2001. Induction of a major leaf acid phosphatase 855 does not confer adaptation to low phosphorus availability in common bean. Plant Physiology $856 \quad$ 125:1901- 1911.

857 Yang SY, Gronlund M, Jakobsen I, Grotemeyer MS, Rentsch D, Miyao A, Hirochika H, Kumar 858 CS, Sundaresan V, Salamin N, Catausan S, Mattes N, Heuer S, Paszkowski U. 2012. 859 Nonredundant regulation of rice arbuscular mycorrhizal symbiosis by two members of the 860 phosphate transporter1 gene family. Plant Cell 24:4236 - 4251.

861 Ye D, Li T, Zheng Z, Zhang X, Chen G, Yu H. 2015. Root physiological adaptations involved 862 in enhancing P assimilation in mining and non-mining ecotypes of Polygonum hydropiper 863 grown under organic P media. Frontiers in Plant Science 6:36.

864 Zhang HW, Huang Y, Ye XS, Xu FS. 2010. Analysis of the contribution of acid phosphatase to 865 P efficiency in Brassica napus under low phosphorus conditions. Science China Life $866 \quad$ Sciences 53:709 - 717. 
867 Zhang Z, Liao H, Lucas WJ. 2014. Molecular mechanisms underlying phosphate sensing, 868 signaling, and adaptation in plants. Journal of Integrative Plant Biology 56:192 - 220.

869

870

875

876

877

878

879

880

881

882

883

884

885

886

887

888

889

890

891

892

893

894

Żebrowska E, Bujnowska E, Ciereszko I. 2012. Differential responses of oat cultivars to phosphate deprivation: plant growth and acid phosphatase activities. Acta Physiologiae Plantarum 34:1251 - 1260.

Żebrowska E, Ciereszko I. 2009. Acid phosphatases role in plant cells phosphate homeostasis. Advances in Cell Biology 36:583 - 599.

\section{Figure legends}

Figure 1. Inorganic phosphate $(\mathrm{Pi})$ concentration in shoots $(\mathrm{A}-\mathrm{C})$ and roots $(\mathrm{D}-\mathrm{F})$. Oat cultivars (Avena sativa L., Arab, Krezus, Rajtar and Szakal) grown for 1, 2 and 3 weeks on a complete nutrient medium $(+\mathrm{P})$, medium with phytic acid $(\mathrm{PA})$ and without phosphate $(-\mathrm{P})$ (means $\pm \mathrm{SD})$. *Differences statistically significant at 0.05

Figure 2. Oat plants after 3 weeks of culture. Oat cultivars (Avena sativa L., cv. Arab, Krezus, Rajtar and Szakal) grown for 3 weeks on a complete nutrient medium $(+\mathrm{P})$, medium with phytic acid (PA) and without phosphate (-P).

Figure 3. Photosynthetic activity $\left(\mathrm{P}_{\mathrm{N}}\right)(\mathrm{A}-\mathrm{C})$, soluble sugars $(\mathrm{D}-\mathrm{E})$ and starch $(\mathrm{F}-\mathrm{G})$ concentration in shoots and roots. Oat cultivars (Avena sativa L., cv. Arab, Krezus, Rajtar and Szakal) grown in a complete nutrient medium $(+\mathrm{P})$, medium with phytic acid $(\mathrm{PA})$ and without phosphate (-P). (means $\pm \mathrm{SD})$. *Differences statistically significant at 0.05 
895 Figure 4. In vivo staining for acid phosphatase activity in root cross sections. Oat cultivars 896 (Avena sativa L., cv. Arab, Krezus, Rajtar and Szakal) cultured for one week on a complete 897 nutrient medium (+P) (A-D) medium with phytic acid (PA) (E-H) and without phosphate

898 (I-L, N-O). The dark red-brown colour indicates acid phosphatase activity in the root tissues, as 899 compared to the heat-killed tissue - control (M).

900

901 Figure 5. Extracellular (A-C) and intracellular acid phosphatase activity in shoots (D-F) and 902 roots (G-I). Oat cultivars (Avena sativa L., cv. Arab, Krezus, Rajtar and Szakal) grown for 1, 2 903 and 3 weeks on a complete nutrient medium $(+\mathrm{P})$, nutrient medium with phytic acid (PA) or 904 without phosphate (-P) (means \pm SD). *Differences statistically significant at 0.05 905

906

907

908

909

910

911

912

913

914

915

916

917

918

919

920

921

922

Figure 6. Profile of APase isoforms in crude protein extracts from shoots and roots. Oat cultivars (Avena sativa L., cv. Arab, Krezus, Rajtar and Szakal) cultured for 3 weeks on a complete nutrient medium $(+\mathrm{P})$, medium with phytate $(\mathrm{PA})$ and without phosphate $(-\mathrm{P})$. Protein extracts from shoots (10 $\mu \mathrm{g}$ protein per lane) and roots (6 $\mu \mathrm{g}$ protein per lane) were run on native discontinuous PAGE and stained for APase activity using 4-methylumbelliferyl phosphate and visualized under UV light.

Figure 7. Inorganic phosphate $(\mathrm{Pi})$ concentration in shoots $(\mathrm{A}-\mathrm{B})$ and roots $(\mathrm{C}-\mathrm{D})$ of plants treated (M) or not treated with AM fungi. Oat cultivars (Avena sativa L., cv. Arab and Krezus) grown for 5 weeks on a sand complete nutrient medium $(+\mathrm{P})$, medium with phytic acid (PA) and without phosphate (-P) non-inoculated or inoculated (M) with Glomus intraradices. Significant differences are indicated by different letters.

\section{Supporting information}


923 Figure S1. Total phosphorus $(\mathrm{Pt})$ content in shoots $(\mathrm{A}-\mathrm{C})$ roots $(\mathrm{D}-\mathrm{F})$ and oat seeds $(\mathrm{G})$. Oat

924 varieties (Avena sativa L., Arab, Krezus, Rajtar and Szakal) were grown for 1, 2 and 3 weeks on

925 complete nutrient medium (+P), medium with phytic acid (PA) and without phosphate (-P).

926 (means $\pm \mathrm{SD}$ ). *Differences statistically important at 0.05

927 Figure S2. Root to shoot ratio of four oat varieties (Avena sativa L., Arab, Krezus, Rajtar and

928 Szakal) grown for 1 - 3 weeks on complete nutrient medium (+P), medium with phytic acid (PA) 929 and without phosphate (-P).

930 Figure S3. Modifications of rhizosphere $\mathrm{pH}$ (with bromocresol purple as indicator) of oat 931 varieties roots (Avena sativa L., Arab, Krezus, Rajtar and Szakal) grown for one week on 932 complete nutrient medium $(+\mathrm{P})$, medium with phytic acid (PA) and without phosphate (-P).

933 Figure S4. Extracellular APase activity kinetic assay, the Lineweaver-Burk plot and the $\mathrm{K}_{\mathrm{m}}$ and $934 \mathrm{~V}_{\max }$ estimated for four oat varieties (Avena sativa L., Arab, Krezus, Rajtar and Szakal) grown 935 for two weeks on complete nutrient medium $(+\mathrm{P})$, medium with phytic acid (PA) and without 936 phosphate (-P).

937

938 Table S1. Growth parameters of four oat (Avena sativa L.) varieties (Arab, Krezus, Rajtar and 939 Szakal) grown for 2 weeks on complete nutrient medium (+P), medium with phytic acid (PA) 940 and without phosphate (-P). *Differences statistically important at 0.05 .

941 Table S2 . Chlorophyll and carotenoids contents in leaves of four oat (Avena sativa L.) varieties 942 (Arab, Krezus, Rajtar and Szakal) grown for 1- 3 weeks on complete nutrient medium $(+\mathrm{P})$, 943 medium with phytic acid (PA) and without phosphate (-P). *Differences statistically important at 9440.05 . 
Figure 1

Inorganic phosphate $(\mathrm{Pi})$ concentration in shoots $(\mathrm{A}-\mathrm{C})$ and roots $(\mathrm{D}-\mathrm{F})$.

Oat cultivars (Avena sativa L., Arab, Krezus, Rajtar and Szakal) grown for 1, 2 and 3 weeks on a complete nutrient medium $(+P)$, medium with phytic acid (PA) and without phosphate (-P) (means $\pm \mathrm{SD}$ ). *Differences statistically significant at 0.05 .
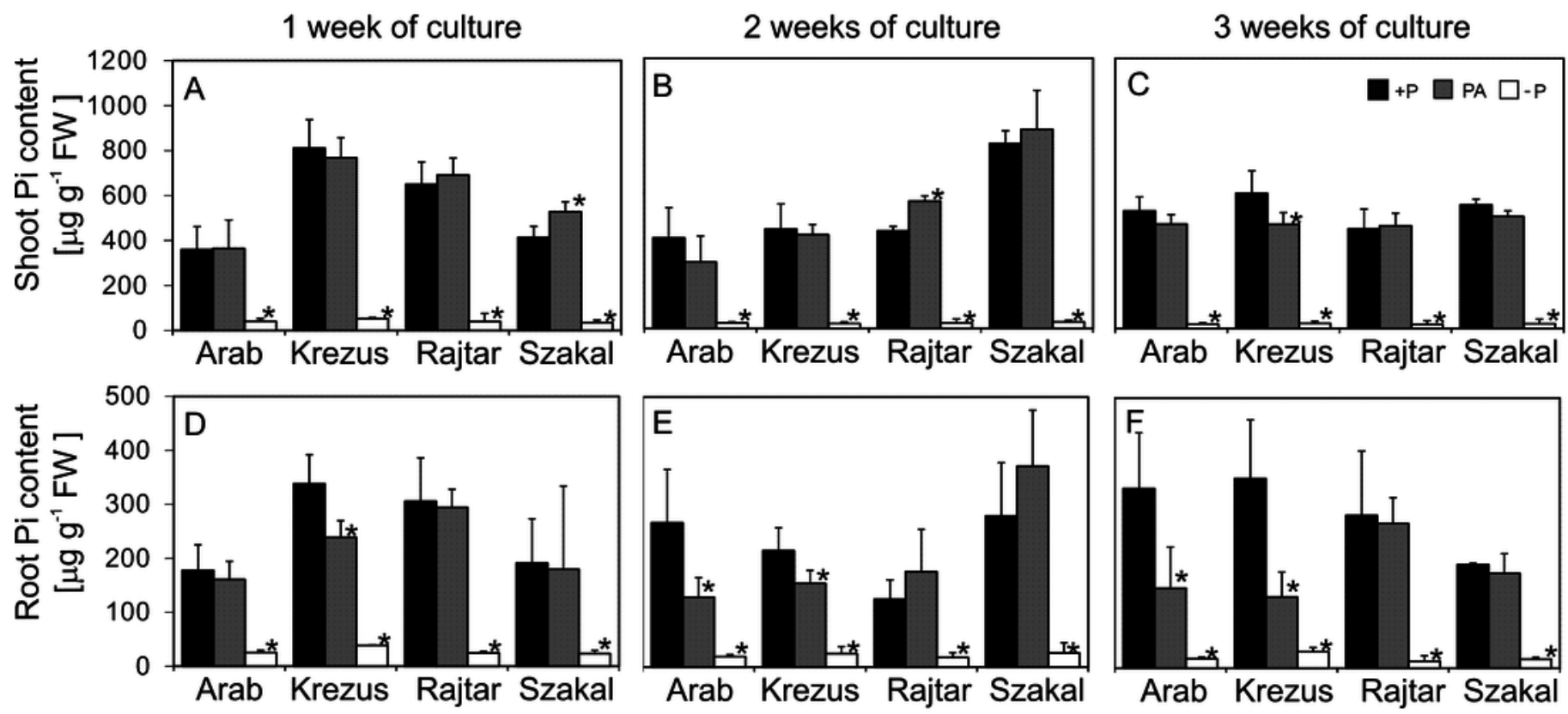
Figure 2

Oat plants growth after 3 weeks of culture.

Oat cultivars (Avena sativa L., cv. Arab, Krezus, Rajtar and Szakal) grown for 3 weeks on a complete nutrient medium $(+P)$, medium with phytic acid (PA) and without phosphate (-P). 

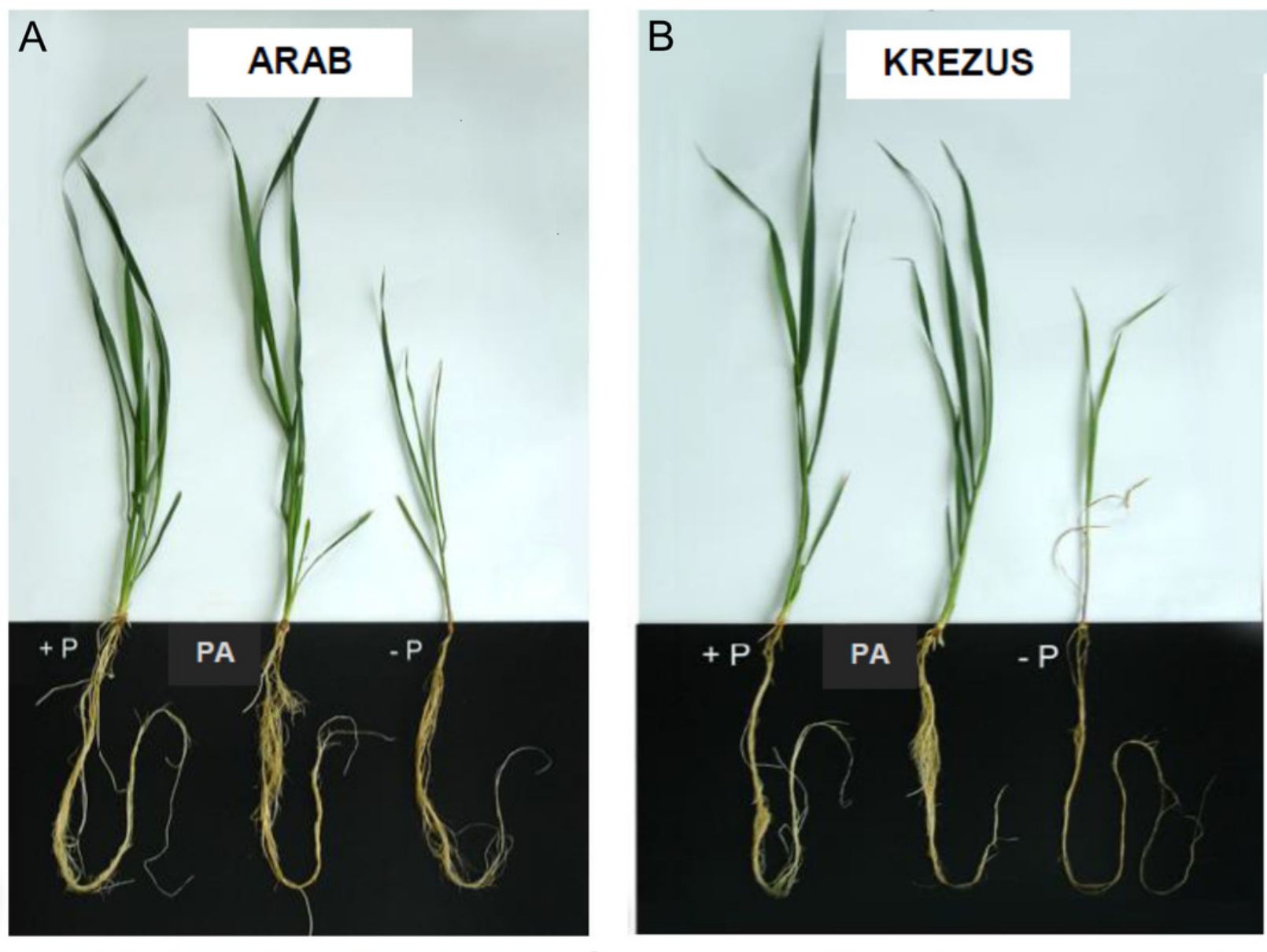

C

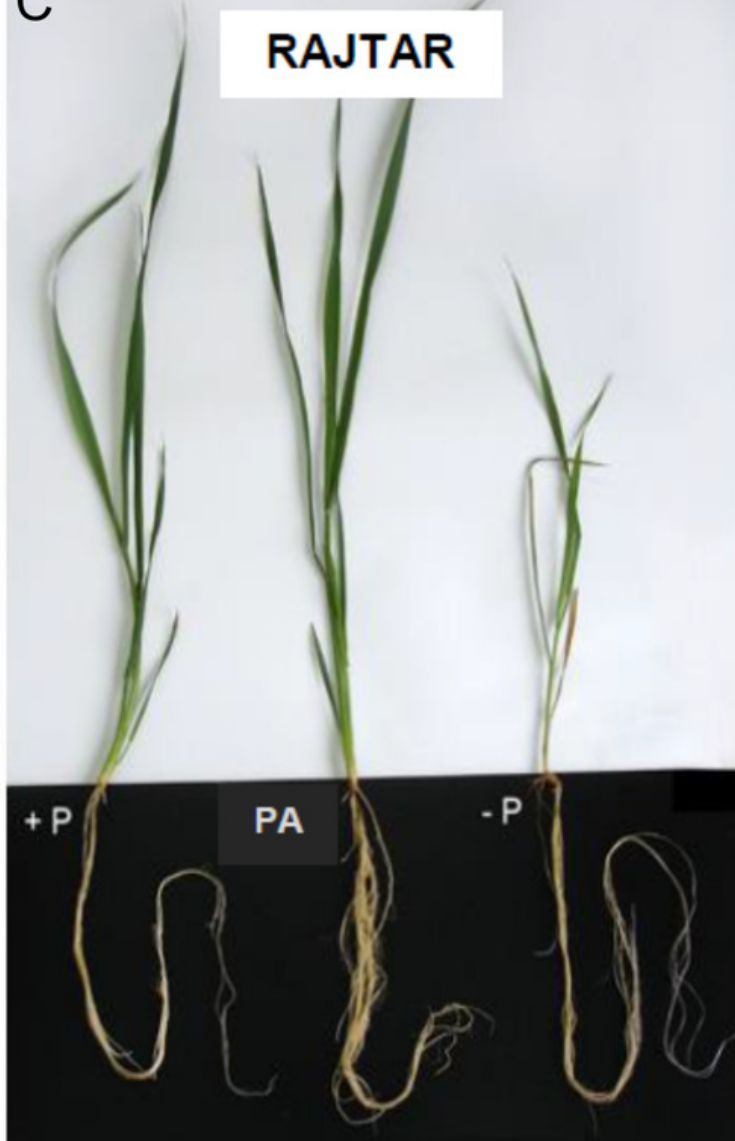

D
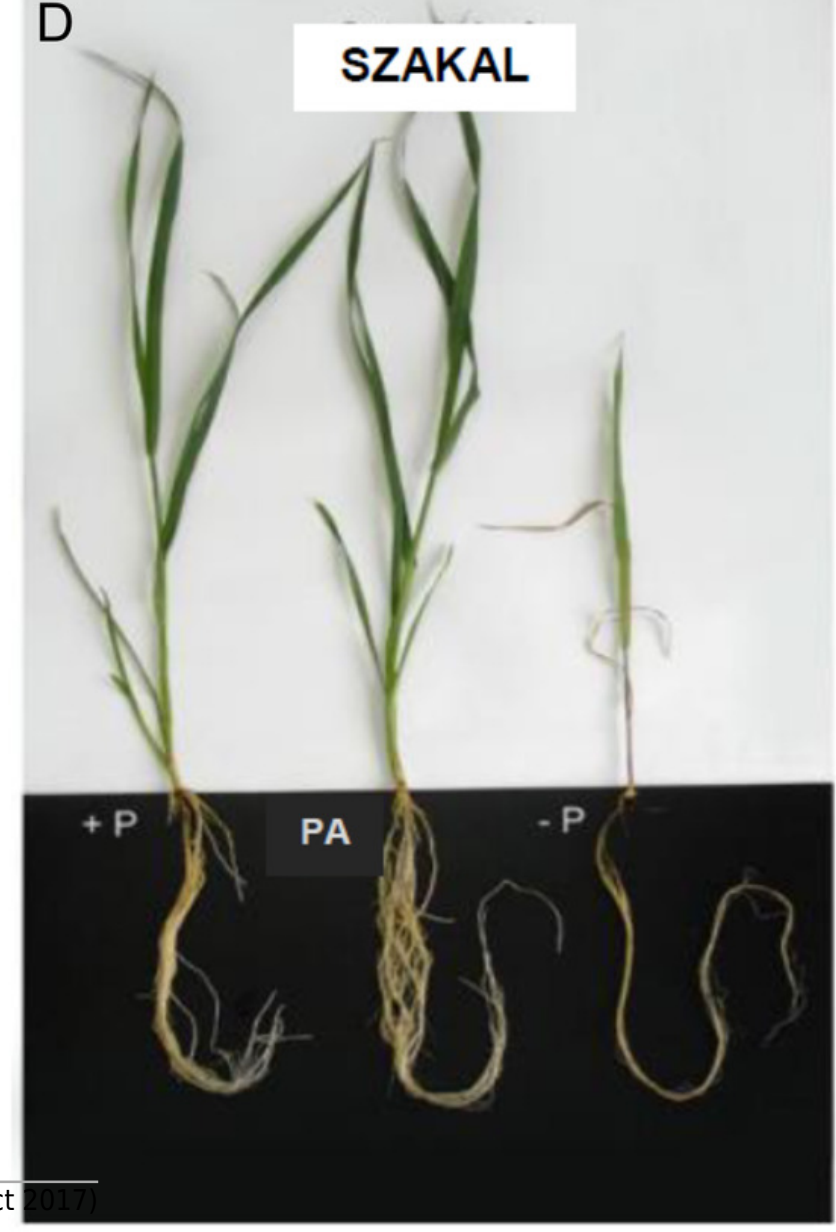
Figure 3

Photosynthetic activity (PN) (A-C), soluble sugars (D-E) and starch (F-G) concentration in shoots and roots.

Oat cultivars (Avena sativa L., cv. Arab, Krezus, Rajtar and Szakal) grown in a complete nutrient medium $(+P)$, medium with phytic acid $(P A)$ and without phosphate $(-P)$. (means \pm SD). *Differences statistically significant at 0.05 .
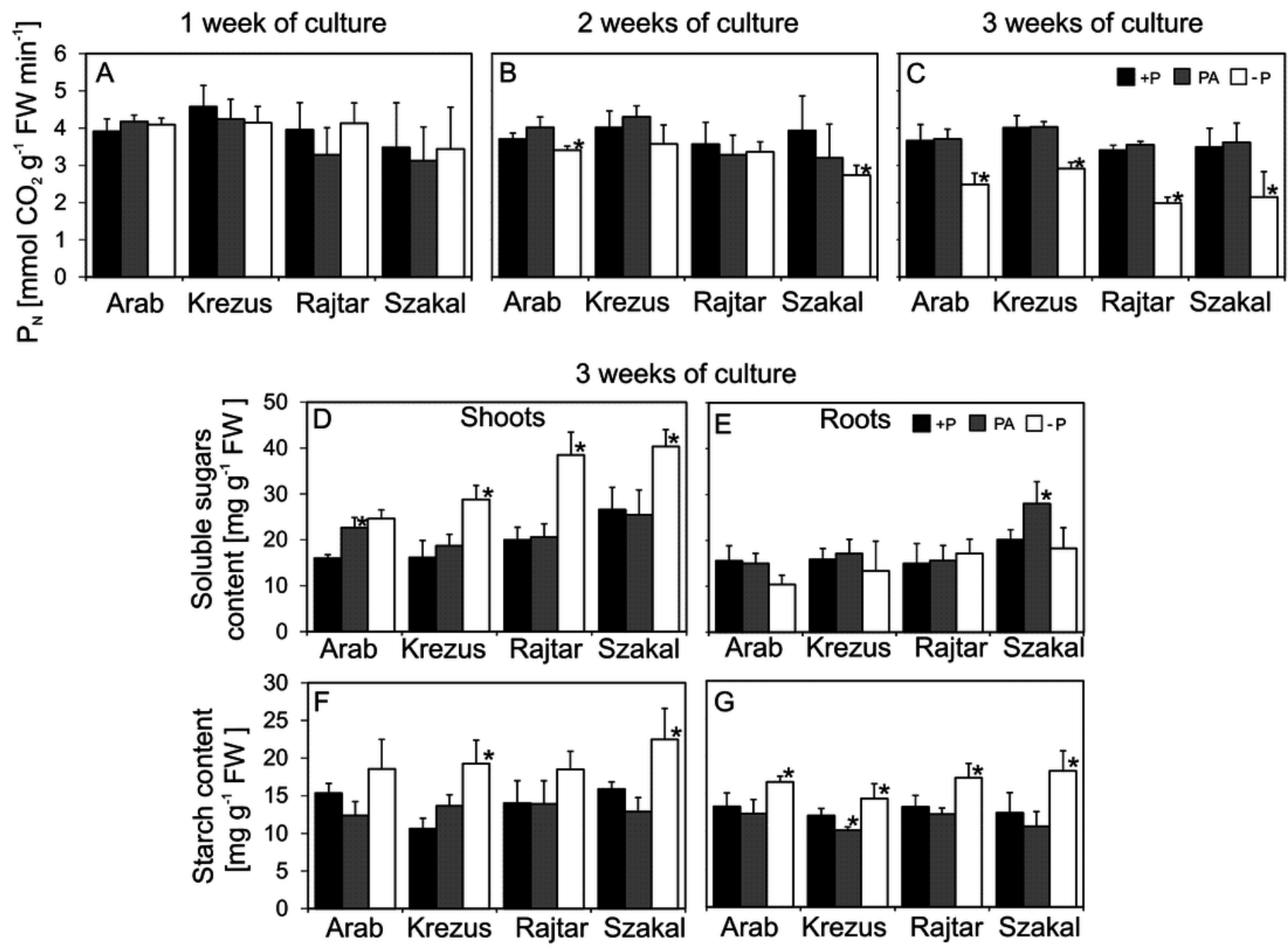


\section{Figure 4}

In vivo staining for acid phosphatase activity in root cross sections.

Oat cultivars (Avena sativa L., Cv. Arab, Krezus, Rajtar and Szakal) cultured for 1 week on a complete nutrient medium (+P) (A-D), medium with phytic acid (PA) (E-H) and without phosphate (-P) (I-L, N-O).The dark red-brown colour indicates acid phosphatase activity in the root tissues, as compared to the heat-killed tissue - control (M). 

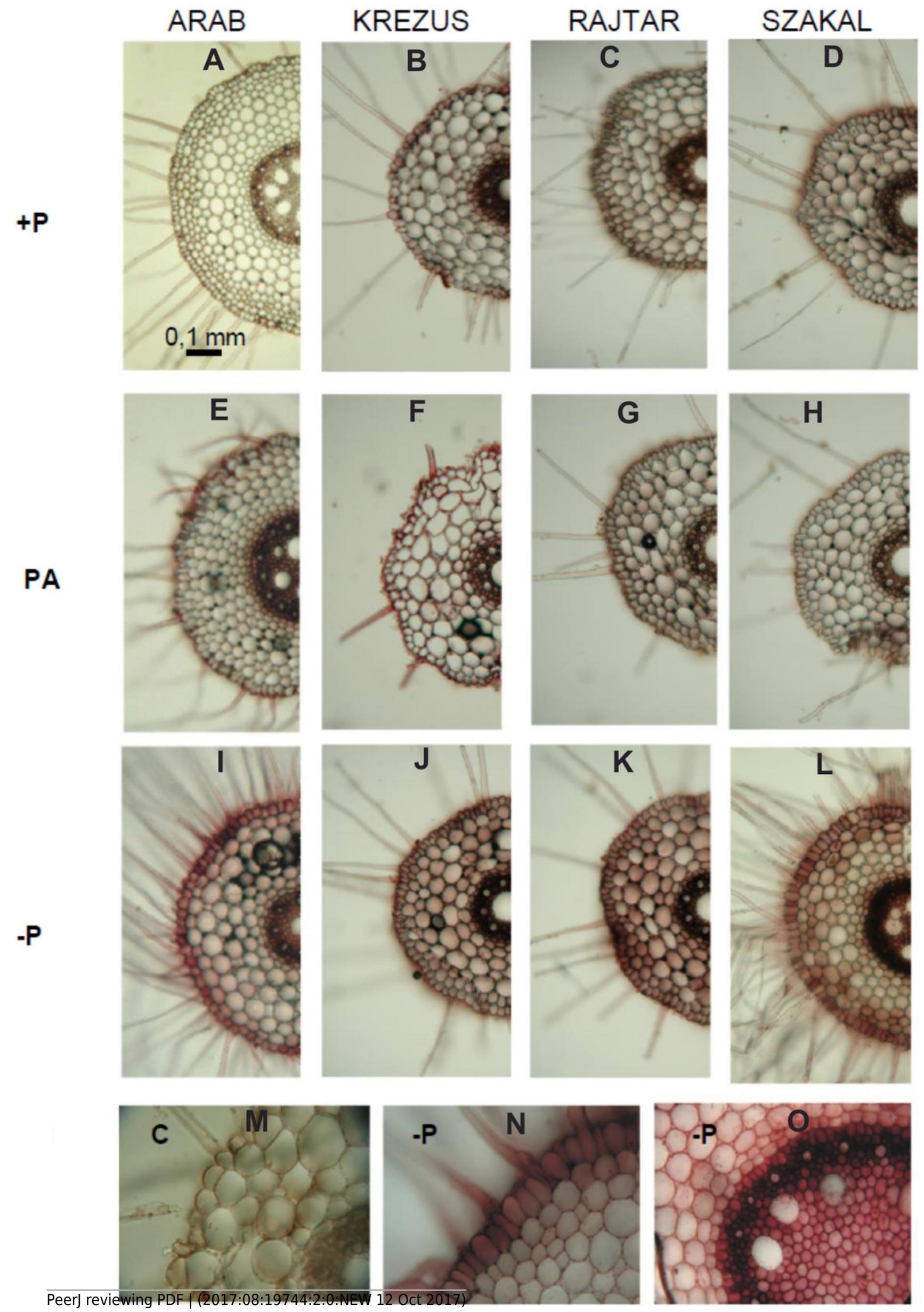


\section{Figure 5}

Extracellular (A-C) and intracellular acid phosphatase activity in shoots (D-F) and roots (G-I).

Oat cultivars (Avena sativa L., cv. Arab, Krezus, Rajtar and Szakal) grown for 1, 2 and 3 weeks on a complete nutrient medium $(+\mathrm{P})$, nutrient medium with phytic acid (PA) or without phosphate $(-P)$ (means \pm SD). *Differences statistically significant at 0.05 .
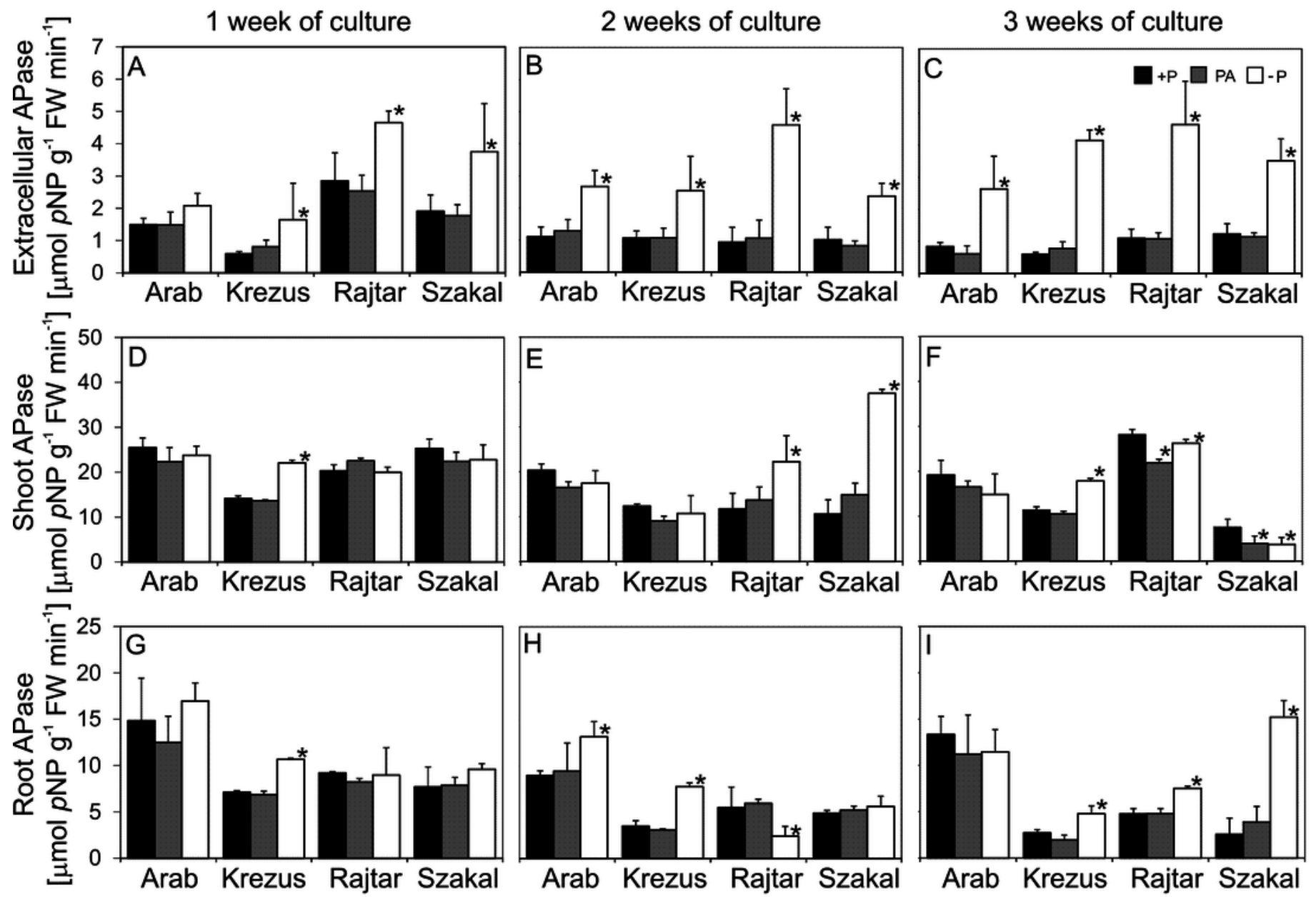


\section{Figure 6}

Profile of APase isoforms in crude protein extracts from shoots and roots.

Oat cultivars (Avena sativa L., cv. Arab, Krezus, Rajtar and Szakal) cultured for 3 weeks on a complete nutrient medium (+P), medium with phytate (PA) and without phosphate (-P).

Protein extracts from shoots ( $10 \mu \mathrm{g}$ protein per lane) and roots ( $6 \mu \mathrm{g}$ protein per lane) were run on native discontinuous PAGE and stained for APase activity using 4-methylumbelliferyl phosphate and visualized under UV light. 

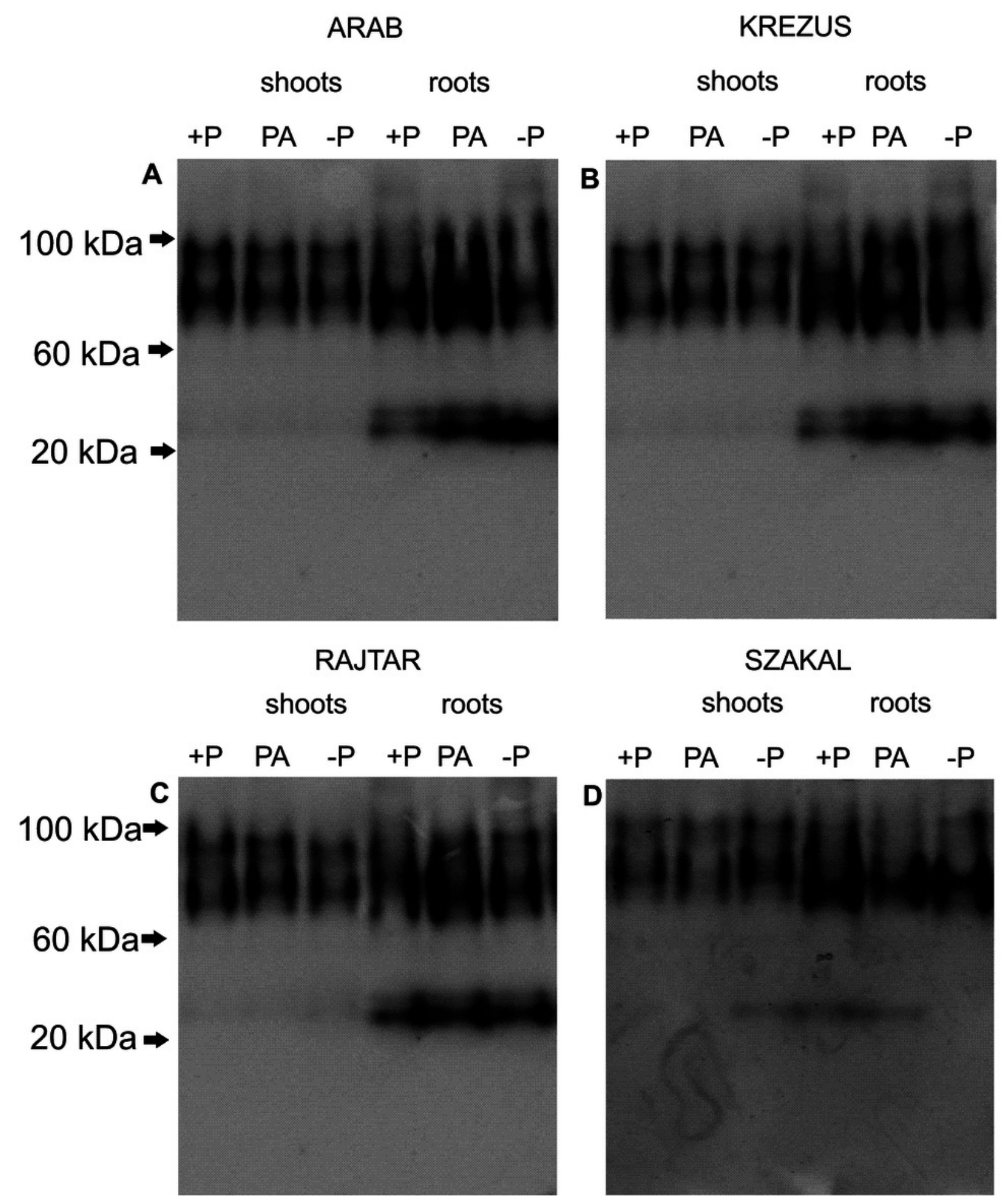
Figure 7

Inorganic phosphate $(\mathrm{Pi})$ concentration in shoots $(\mathrm{A}-\mathrm{B})$ and roots $(\mathrm{C}-\mathrm{D})$ of plants treated $\left({ }_{M}\right)$ or not treated with AM fungi.

Oat cultivars (Avena sativa L., Cv. Arab and Krezus) grown for 5 weeks on a sand complete nutrient medium $(+P)$, medium with phytic acid $(P A)$ and without phosphate $(-P)$ noninoculated or inoculated $\left(_{\mathrm{M}}\right.$ ) with Glomus intraradices. Significant differences are indicated by different letters.
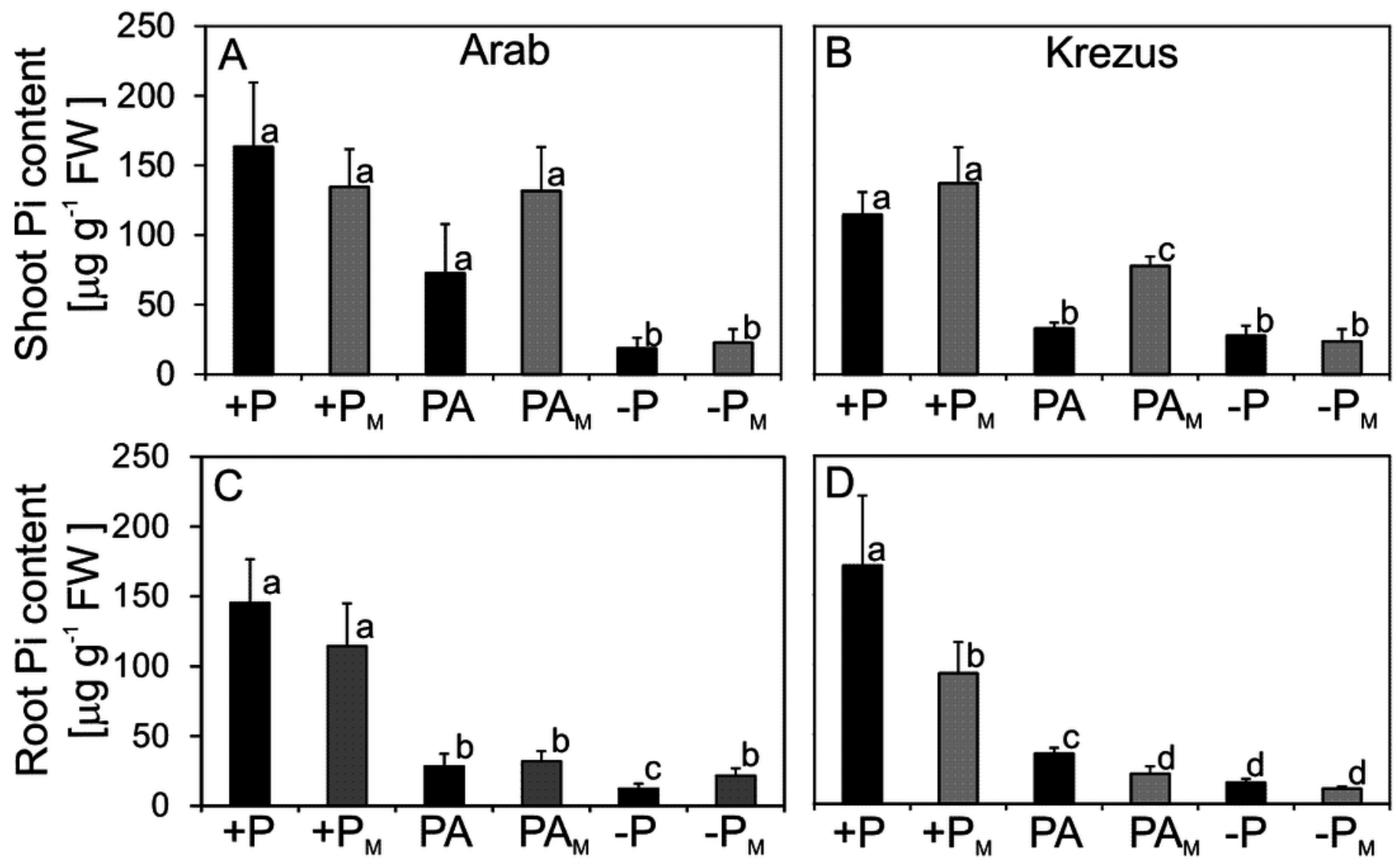


\section{Table $\mathbf{1}$ (on next page)}

Oat cultivars growth parameters

Growth parameters of oat varieties (Avena sativa L., Arab, Krezus, Rajtar and Szakal)

cultured for 3 weeks on complete nutrient medium (+P), medium with phytic acid (PA) and without phosphate (-P). 


\begin{tabular}{|c|c|c|c|c|c|c|c|c|c|c|c|c|}
\hline \multirow[b]{2}{*}{ PARAMETER } & \multicolumn{3}{|c|}{ ARAB } & \multicolumn{3}{|c|}{ KREZUS } & \multicolumn{3}{|c|}{ RAJTAR } & \multicolumn{3}{|c|}{ SZAKAL } \\
\hline & $+P$ & PA & $-P$ & $+P$ & PA & $-P$ & $+P$ & PA & $-P$ & $+P$ & PA & $-P$ \\
\hline Shoot fresh mass [g] & 4.10 & 3.63 & $0.97^{*}$ & 3.45 & 4.14 & $0.57^{*}$ & 3.58 & 3.61 & $0.57^{*}$ & 6.49 & 5.62 & $0.92^{*}$ \\
\hline Root fresh mass [g] & 2.08 & 1.84 & 1.39 & 2.27 & 2.43 & $1.00^{*}$ & 1.68 & 2.22 & $0.81^{*}$ & 2.87 & 2.47 & $0.75^{\star}$ \\
\hline $\operatorname{LAR}\left[\mathrm{cm}^{2} \mathrm{~A} \mathrm{~g}^{-1} \mathrm{~W}\right]$ & 19.2 & 19.1 & $16.4^{*}$ & 20 & 16.3 & $12.7^{*}$ & 21.6 & 22.6 & 25.2 & 17.4 & 19.4 & 19.9 \\
\hline SWR [g WS g-1W] & 0.7 & 0.7 & $0.4^{*}$ & 0.5 & 0.6 & $0.3^{*}$ & 0.7 & $0.6^{*}$ & $0.5^{*}$ & 0.6 & 0.6 & $0.5^{*}$ \\
\hline $\begin{array}{c}\text { ULR } \\
{\left[\mathrm{g}^{-1} \Delta \mathrm{dW} \mathrm{cm}^{2} \mathrm{~A}^{-1} \text { week }^{-1}\right]}\end{array}$ & 0.003 & 0.003 & $0.005^{*}$ & 0.003 & 0.004 & $0.001^{*}$ & 0.003 & 0.003 & 0.003 & 0.004 & 0.003 & 0.004 \\
\hline $\begin{array}{c}\text { RGR } \\
{\left[\mathrm{g} \Delta \mathrm{dW} \mathrm{gW}^{-1} \text { week }^{-1}\right]}\end{array}$ & 0.06 & 0.05 & $0.08^{*}$ & 0.06 & 0.06 & $0.02^{*}$ & 0.07 & 0.07 & 0.07 & 0.07 & 0.06 & 0.06 \\
\hline Root diameter [mm] & 1.3 & 1.2 & $0.9^{*}$ & 1.2 & 1.3 & $0.7^{*}$ & 1.1 & 1.2 & $0.7^{*}$ & 1.4 & 1.3 & $0.7^{*}$ \\
\hline Root area $\left[\mathrm{cm}^{2}\right]$ & 16.2 & 14.9 & 15.7 & 18.6 & 18.8 & $13.9^{*}$ & 15.2 & 18.9 & $12.3^{*}$ & 20.0 & 18.9 & $11.4^{*}$ \\
\hline
\end{tabular}

2

3 *Differences statistically important at 0.05 


\section{Table 2 (on next page)}

Growth parameters of oat plants (Avena sativa L. Cv. Arab, Krezus) inoculated ${ }_{M}$ ) or not inoculated with Glomus intraradices. 


\begin{tabular}{|c|c|c|c|c|c|c|}
\hline \multicolumn{7}{|c|}{ ARAB } \\
\hline Parameter & $+P$ & $+P_{M}$ & PA & $\mathbf{P A}_{M}$ & $-P$ & $-P_{M}$ \\
\hline Shoot height[cm] & $62.0^{a}$ & $64.8^{a}$ & $59.4^{a}$ & $65.2^{\mathrm{a}}$ & $65.1^{\mathrm{a}}$ & $62.1^{\mathrm{a}}$ \\
\hline Root length [cm] & $14.3^{a}$ & $17.6^{a}$ & $22.8^{b}$ & $23.2^{\mathrm{b}}$ & $19.5^{a}$ & $18.1^{a}$ \\
\hline Shoot fresh mass [g] & $8.00^{a}$ & $8.24^{a}$ & $8.71^{a}$ & $8.13^{a}$ & $4.26^{b}$ & $4.6^{b}$ \\
\hline Root fresh mass [g] & $2.67^{a}$ & $1.8^{\mathrm{a}}$ & $1.56^{a}$ & $1.97^{a}$ & $3.82^{b}$ & $2.69^{a}$ \\
\hline \multicolumn{7}{|c|}{ KREZUS } \\
\hline Shoot height[cm] & $64.1^{\mathrm{a}}$ & $63.9^{a}$ & $69.8^{a}$ & $67.9^{a}$ & $60.9^{a}$ & $62.5^{a}$ \\
\hline Root length[cm] & $16.9^{a}$ & $17.8^{a}$ & $20.5^{b}$ & $23.2^{b}$ & $17.9^{a}$ & $17.9^{a}$ \\
\hline Shoot fresh mass [g] & $8.1^{\mathrm{a}}$ & $7^{a}$ & $10^{a}$ & $18.2^{\mathrm{b}}$ & $4.7^{c}$ & $7.7^{a}$ \\
\hline Root fresh mass [q] & $2.34^{a}$ & $1.88^{a}$ & $3.72^{\mathrm{a}}$ & $5.82^{b}$ & $1.78^{a}$ & $2.57^{\mathrm{ac}}$ \\
\hline
\end{tabular}

2

3 Oat varieties (Arab and Krezus) grown for 5 weeks on sand watered with complete 4 nutrient medium $(+P)$, medium with phytic acid (PA) or medium without phosphate 5 (-P) not inoculated or inoculated (м) with Glomus intraradices. Different letters indicate 6 significant differences $(P<0.05)$. 